\title{
Surface morphology and backscattering of ice-ridge sails in the Baltic Sea
}

\author{
A. T. MANNINEN * \\ Finnish Institute of Marine Research, P.O. Box 33, FIN-00931 Helsinki, Finland
}

\begin{abstract}
The triangular shape of an ice-ridge sail in the Baltic Sea was studied statistically. The dimensions and orientation of individual ice blocks were measured in several ridges. All measurements were carried out from the standpoint of backscattering research. The results confirm that given geometrical properties of the two sides of ice ridges are in general not equal. A slight negative correlation was found between the slope angle and width of the sail. All three orientations and all three size parameters of ice blocks on both sides of the ridges studied can be considered as normally distributed. A log-normal distribution, however, fits slightly better the dimensions of the orientationally best rectangular approximations of the polygonal main facets of flat ice blocks. There is almost no correlation between any two of these six variables. Only the width and length of the main-facet rectangle have a vague positive interdependence. Three-dimensional modelling of ice ridges is essential, since the total side-facet area visible is typically at least as large as the total main-facet area. Calculated incidence-angle distributions show that the broad distributions of orientations and dimensions make different ridges appear very similar on radar images.
\end{abstract}

\section{INTRODUCTION}

Ice ridges constitute a major problem for winter shipping in the Baltic Sea, where only first-year low-salinity ice occurs. They are long but narrow piece-wise linear or curvilinear) features consisting of broken ice pieces above (sail) Figs 1-3) and below (keel) the water surface. According to Archimedes' law there is a correlation between the ice mass above and below the water level. Therefore knowledge about the sail will help in estimating the degree of difficulty in penetrating the ridge.

The sail of the ridge is the only part detectable on $\mathrm{X}$ or C-band radars. SAR (synthetic aperture radar) images are the most promising tool for detecting ridged areas, since they can be obtained almost independently of weather conditions and without the need for daylight. Even satellite SARs can have a resolution of a few tens of meters. The high contrast between the broken ice blocks in ridges and the surrounding level ice helps distinguish sub-pixel-size ridges. In order to understand SAR imagery it is necessary to study the backscattering from ice ridges in relation to the surface structure.

Ice ridges have been studied extensively in the Baltic Sea for many years, but emphasis has been primarily on mass and strength Palosuo, 1975; Keinonen, 1976, 1977; Kankaanpää, 1988, 1989, 1991; Leppäranta and others,

\footnotetext{
Present address: VTT Automation, Space Technology, P.O. Box 13031, 02044 VTT, Finland.
}

1990; Veitch and others, 1991; Leppäranta and Hakala, 1992; Lensu, unpublished). The ice-block and sail-shape measurements made for this purpose do not include all the parameters needed for backscattering studies. In addition, some properties have been measured that preclude the results from backscattering calculations although they are very good for the general structure analysis of ice ridges.

The backscattered signal is highly sensitive to orientation of the ice blocks of ridge sails Ulaby and others, 1982; Fung, 1994). When making statistical models for the structure of ridge sails it is practical to approximate the ice blocks with flat rectangular polyhedrons, which is a good estimate especially for new ridges (Figs 1 and 3 ). This simplification means that the shape and orientation of an ice block require only six statistical parameters: three for size and three for orientation. If general polyhedrons were used, one would need to know the direction three angles) and distance from a fixed point to each corner of the polyhedron. Statistics for the number of corners would also be needed. To measure a statistically sufficient number of all these parameters is not possible in practice. Moreover, backscattering models would become much more complicated, and calculations more time-consuming, without the simplification afforded by rectangular polyhedrons. Due to the orientational sensitivity of the radar signal it is essential that the rectangular approximation of the polygons also closely represents the orientation of the sides, not just the area of the polygons Manninen, unpublished c). The measurements reported in this paper 


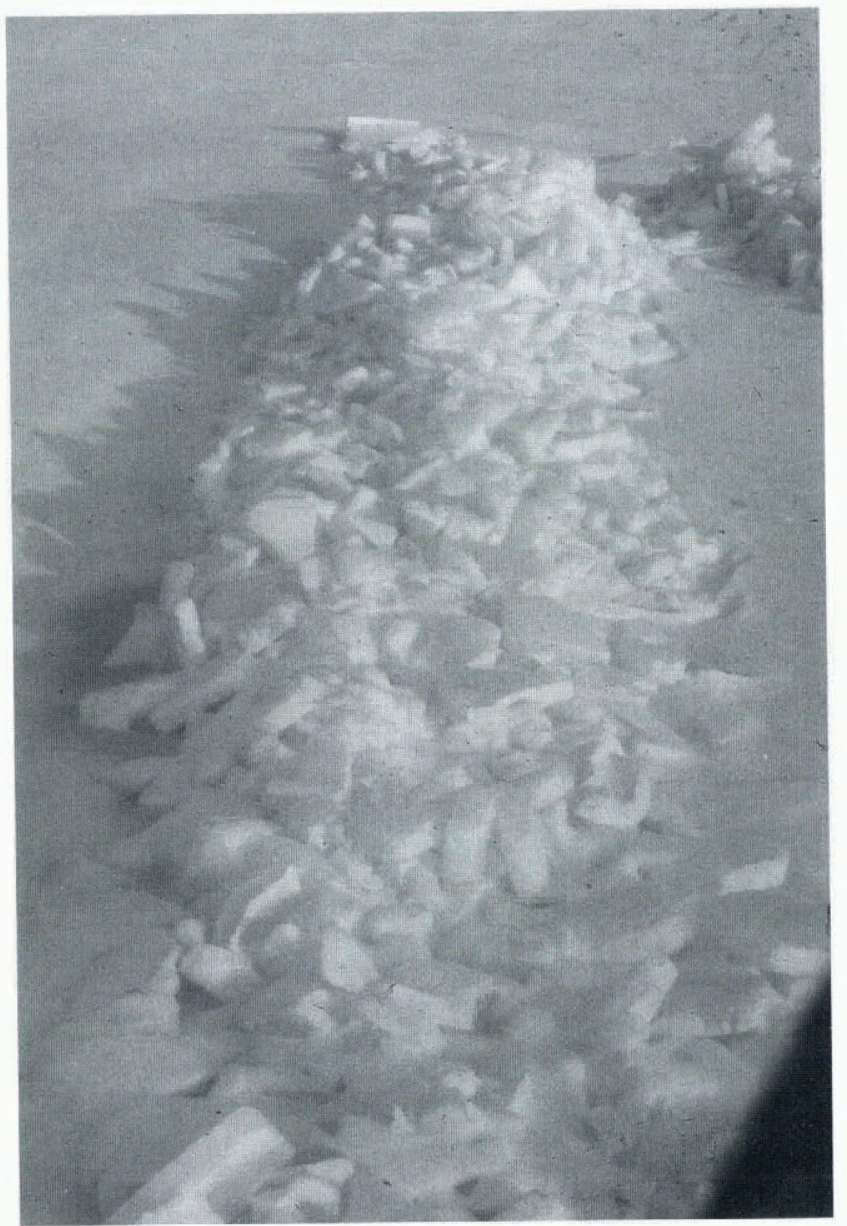

Fig. 1. Newly formed finger-rafled ice ridge in the Bay of Bolhnia, February 1992. The shadow reveals how difficult it is to measure the height of a ridge from a single laser profilometer line, as pointed out by Tucker and Govoni (1981). The ice-block thickness is about $0.1 \mathrm{~m}$. The screw-like form of this sail is obvious.

were all made for the purpose of backscattering calculations Manninen, 1993, 1994, unpublished a; Manninen and Rantasuo, unpublished).

All the results presented here have been obtained in two Application Oriented Pilot Projects accepted by
ESA: the international PIPOR Programme for International Polar Oceans Research) project and the Finnish project, "Operational sea-ice charting using ERS-1 SAR images" (OSIC) (Leppäranta and others, 1992; Grönvall and Seinä, 1994).

\section{GENERAL SHAPE OF AN ICE-RIDGE SAIL}

The maximum height of ice ridges in previous studies has varied from 0.1 to $3.5 \mathrm{~m}$ (Palusuo, 1974; Keinonen, 1976; Kankaanpää, 1988, 1989, 1991; Leppäranta and others, 1990; Lensu, unpublished). The slope angle of the sides of the ridges has varied from $1^{\circ}$ to $64^{\circ}$ or $10^{\circ}$ to $50^{\circ}$ depending on the definition of the slope angle. Likewise the width of the sail has varied from 1 to $34 \mathrm{~m}$ depending on the definitions used. The definition of the slope angle is not always given, but in older Baltic Sea measurements it seems to have been the angle that subjectively best fits the obvious part of the ridge sail, and is thus also relevant for backscattering calculations (Palosuo, 1974). Later the slope angle was defined as the angle that together with the ridge height produces a triangle with an area equal to the cross-sectional area of one side of the ridge sail, which also includes the surroundings of the obvious part of the ridge sail Kankaanpää, 1991). Therefore the slope angles of the latter definition are systematically lower than the previous ones. From the point of view of backscattering it is important to know the slope angle of the actual sail, not the slightly inclined surroundings. Moreover, an average value that combines the slope angle of these two parts has no relevance for backscattering. Also, a single value for a ridge is not sufficient; knowledge of the statistics of slope angles is also required. Therefore the general shape of a ridge sail has been studied more closely and the results are presented here.

The general ridge-shape data reported in this paper are part of the field experiments carried out in the OSIC project. The study area in the northeastern part of the Bay of Bothnia $\left(65^{\circ} 14.9^{\prime} \mathrm{N}, 24^{\circ} 13.9^{\prime} \mathrm{E}\right)$ was the edge of an old, deformed ice field. The measurements were carried out in February 1993 (Manninen, 1993). The direction of the ridge varied markedly due to its serpentine sail (Fig.

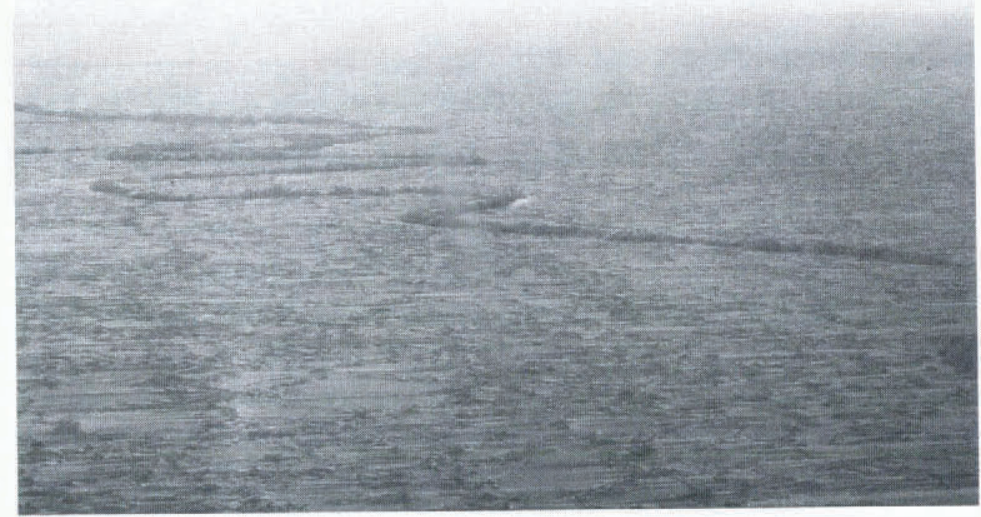

Fig. 2. General outline of an old finger-rafted ice ridge in the Bay of Bothnia, February 1993. The direction of the wind is clearly seen in the structure of the snow cover. The shape of this sail was studied in detail. Also a number of ice-block orientation measurements were carried out on this ridge. 


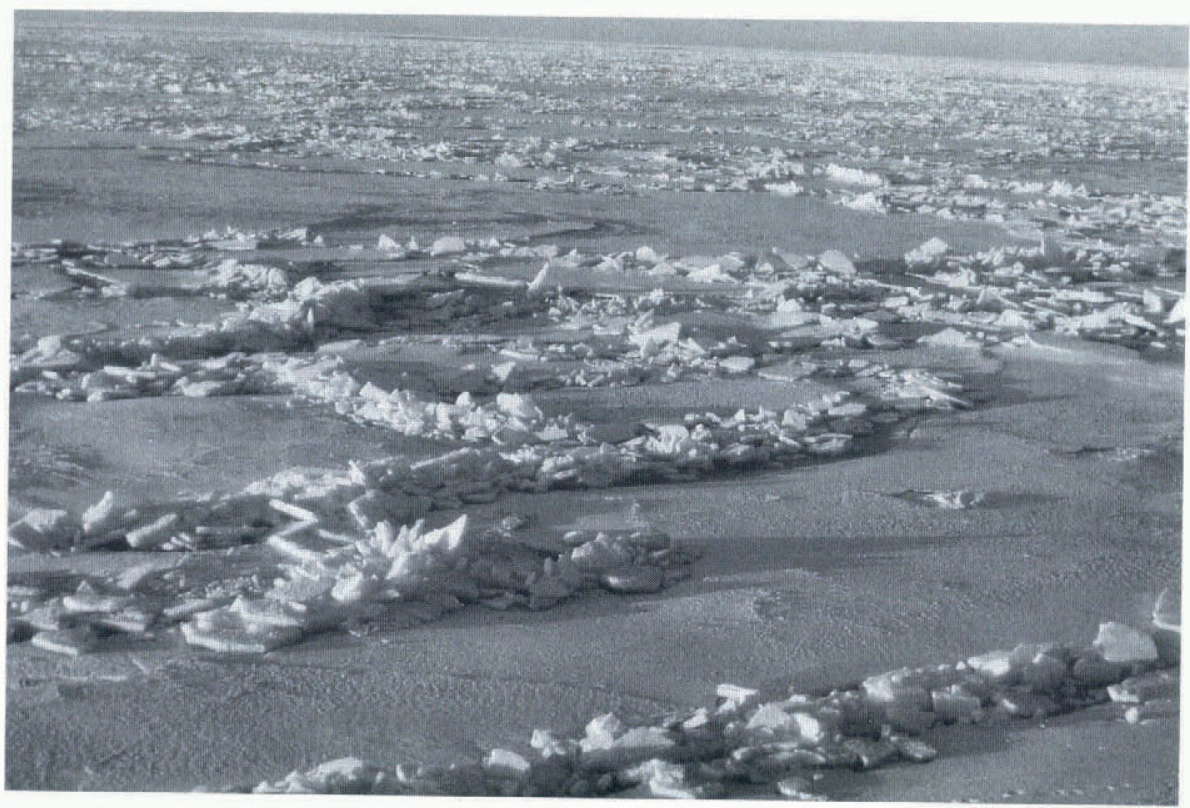

Fïg. 3. Net-like rubbled ice in the Sea of Bothnia, March 1994. The sail height is roughly $0.5 \mathrm{~m}$. Ice-block orientations were also measured in this kind of ice.

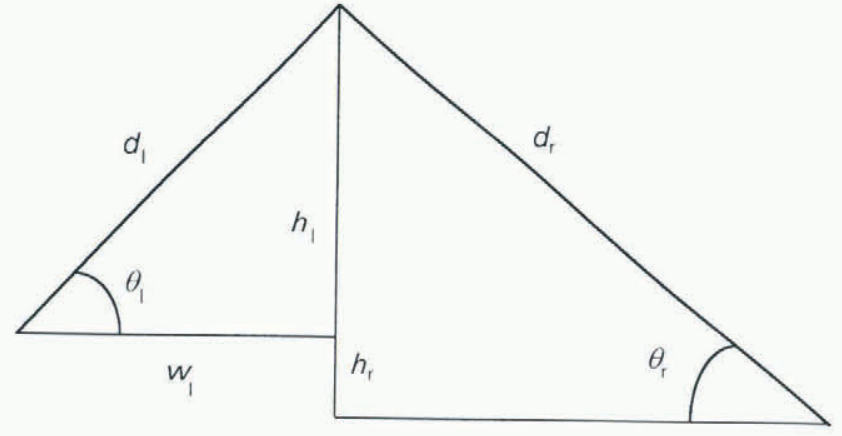

$W_{r}$

Fig. 4. Paramelers describing the cross-section of an iceridge sail. All the parameters involied (slope angle $\theta$. height $h$, width $w$ and slope length d) can have different values on the lefi- and righthand sides.

2 , but an average was roughly northeast or north.

The general cross-section of an ice-ridge sail can be defined by a sequence of slices each comprising two joining triangles. The cross-section triangles are characterized using the slope angles and side dimensions shown in Figure 4. In practice, the most reliable result is obtained by measuring slope angles and slope lengths.
These were measured in 102 places at about $2 \mathrm{~m}$ intervals along the ridge studied Fig. 2). Measurements were carried out simply by resting flat rods on the outermost ice-block edges on both sides of the ridge, so that on visual inspection the angle of the rod corresponded well with the average sail slope. Slope lengths were measured using the scale on the rods, and slope angles were obtained by checking the inclination of the rod using an inclinometer. The resolutions of the measurements were $0.01 \mathrm{~m}$ and 1 , respectively. Positioning of the rods was subjective. Slope width and height were calculated according to Figure 4 by multiplying the slope length by the cosine and sine of the slope angle. The results are given in Table 1 and Figures 57.

Figure 5 reveals the finger-like structure of the base of the ice-ridge sail, which is serpentine in the vertical direction. On average, the flat ice surface at the base of the ridge sail is slightly higher on the western than on the eastern side. This is natural, since the ridge has been formed by an override of the western ice sheet due to hard westerly winds. The average height-difference magnitude is $0.16 \mathrm{~m}$, which is close to the thickness of the ice floes in the flat-ice area. In general, the slope angle and length do not seem to obey log-normal or normal distribution very well. On the western side these properties pass the tightest risk level checked $(0.10)$ of log-normal distribution, but

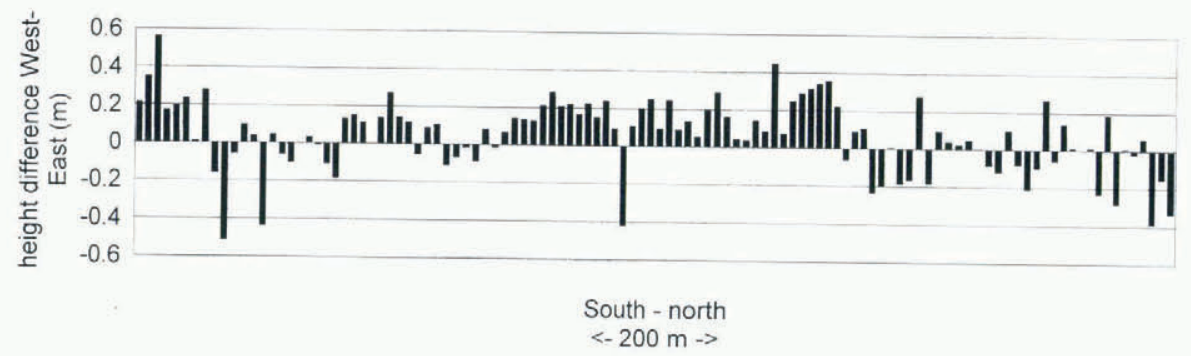

Fig. 5. Height difference between west and east side slopes along the ridge direction. The distance between successive columns is about $2 \mathrm{~m}$. 
Table 1. Average values and standard deviations of ice-ridge sail-slope angle, length, height and width of both sides of the studied ridge and the height difference of the two sides. The risk level at which the parameters pass the Lilliefors test for normal and log-normal distribution is also given. The tightest criterion checked is 0.10

Western side (blue) Eastern side (red)

West-east West-east height magnitude difference of height difference

\begin{tabular}{|c|c|c|c|c|c|c|c|c|c|c|}
\hline & length & angle & height & width & length & angle & height & widih & & \\
\hline Average & $2.48 \mathrm{~m}$ & $30^{\circ}$ & $1.11 \mathrm{~m}$ & $2.16 \mathrm{~m}$ & $2.39 \mathrm{~m}$ & $30^{\circ}$ & $1.06 \mathrm{~m}$ & $2.08 \mathrm{~m}$ & $0.06 \mathrm{~m}$ & $0.16 \mathrm{~m}$ \\
\hline Standard deviation & $0.81 \mathrm{~m}$ & $14^{\circ}$ & $0.32 \mathrm{~m}$ & $0.90 \mathrm{~m}$ & $0.85 \mathrm{~m}$ & $15^{\circ}$ & $0.34 \mathrm{~m}$ & $0.94 \mathrm{~m}$ & $0.19 \mathrm{~m}$ & $0.12 \mathrm{~m}$ \\
\hline $\begin{array}{l}\text { Risk level for } \\
\text { normality }\end{array}$ & 0.10 & - & 0.10 & 0.10 & - & - & 0.10 & 0.05 & 0.10 & - \\
\hline $\begin{array}{l}\text { Risk level for log- } \\
\text { normal distribution }\end{array}$ & 0.10 & 0.10 & - & - & - & 0.01 & 0.01 & & - & - \\
\hline
\end{tabular}

on the eastern side only the slope angle is roughly lognormal with a risk level of 0.01 (Table 1). The height and height difference are normally distributed according to Table 1.

The two triangles of each cross-section of the ridge are not generally similar (Fig. 6), only their sail heights having a clear correlation. If the slope angles of both sides are smaller than about $50^{\circ}$ there is no obvious correlation. However, if the slope angle of one side exceeds $50^{\circ}$ the
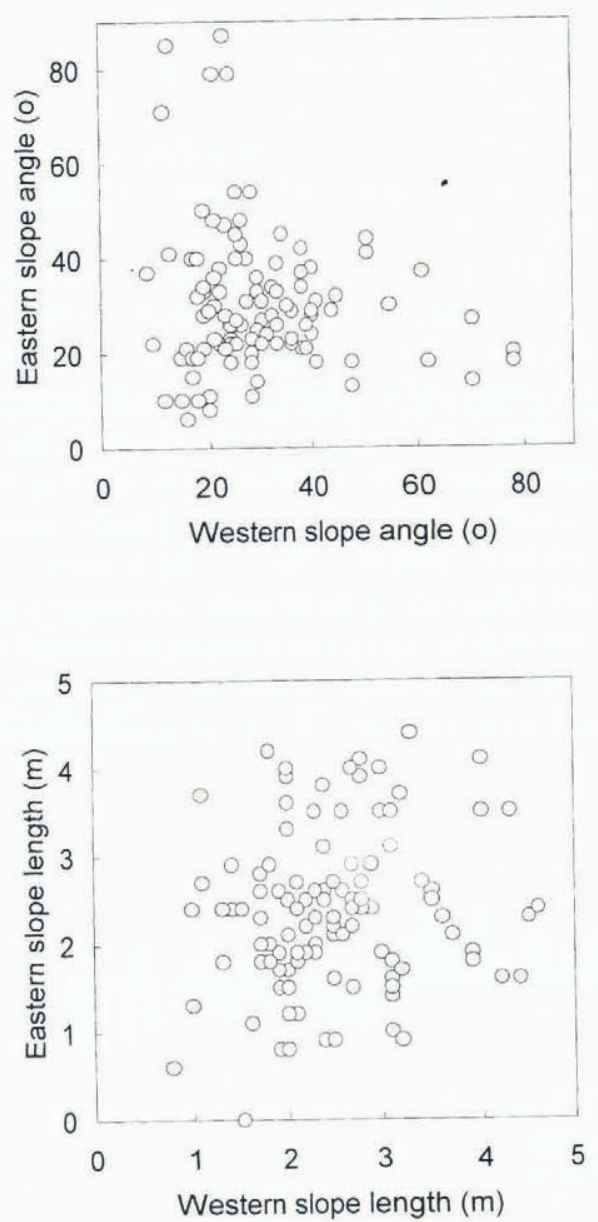

other is smaller than $50^{\circ}$, showing a negative interdependence when either of the sides is very steep. Although the direct correlation of the two sides is rather weak, the average slope angle is exactly the same, $30^{\circ}$, for both sides (Table 1). Even the average slope lengths of the two sides do not markedly deviate from each other. This is not surprising, as the ice blocks on both sides of the ridge are formed from the same ice field and have similar piling properties.
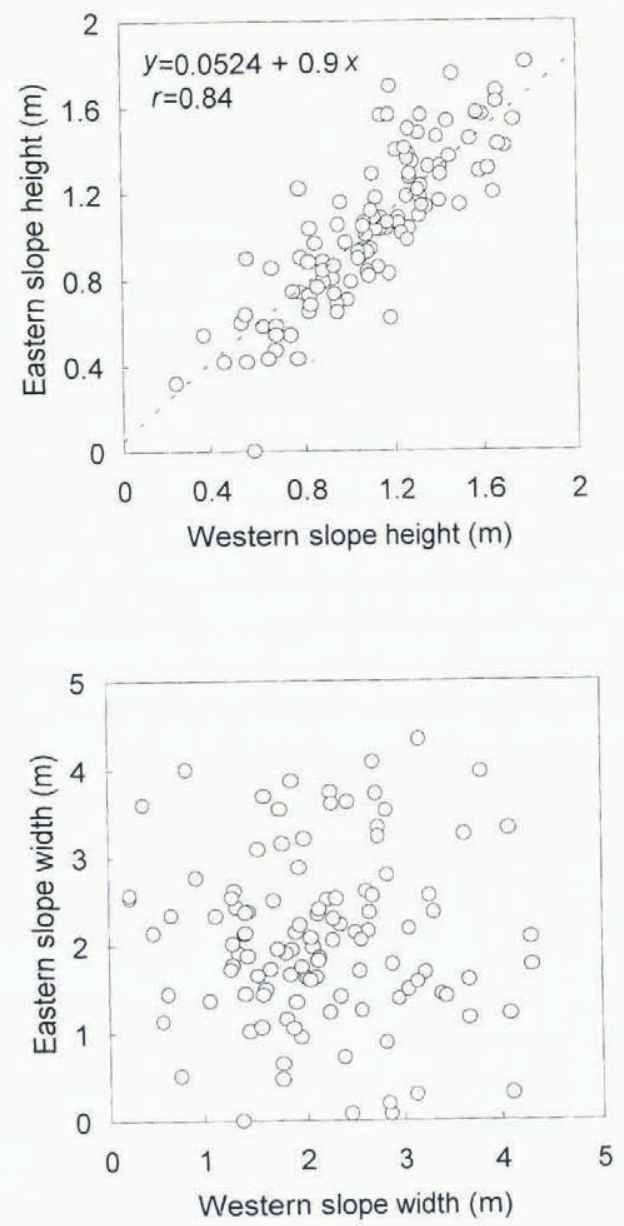

Fig. 6. Correlation of slope angles, slope lengths and heights and widths of both sides of the sail of the ridge east of that in Figure 2. 

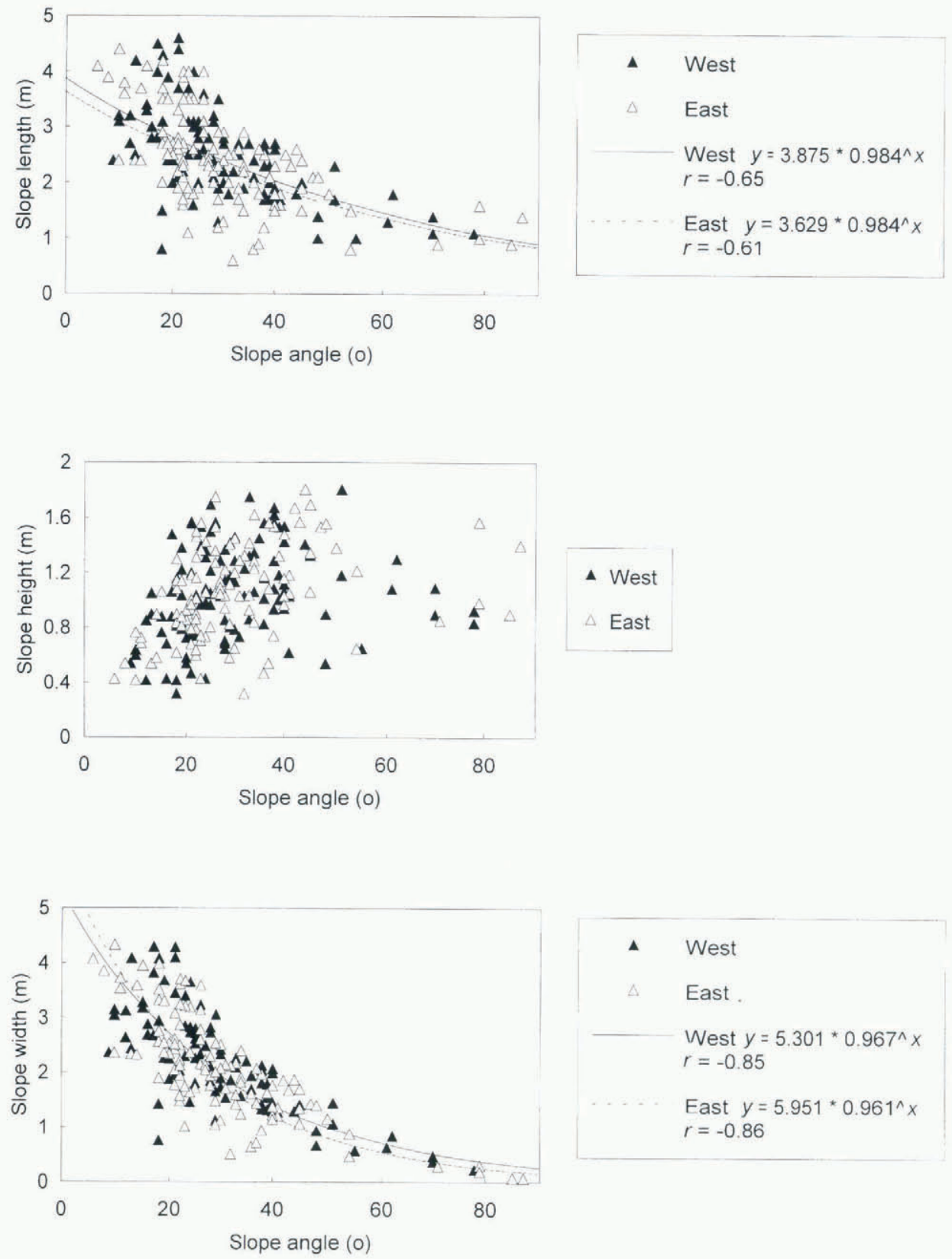

Fig. 7. Correlation of slope angle, slope length, and height and width of boll sides of the ridge of Figure 2.

The slope angle does not depend strongly on the other three slope parameters width, height and length) Fig. 7). The highest correlation is between slope width and slope angle, indicating that the steepest slopes correspond to the narrowest sails, which is understandable since in Nature the ice-block size has an upper limit. However, if the slope angle is smaller than about $30^{\circ}$, the width is only vaguely dependent on it. As the slope angle increases, so does the largest possible slope height.

Although there is virtually no correlation between the height difference of the two sides of the ridge and the slope angle, height and width, the steepest slopes (slope angle $>50^{\circ}$ have a slight tendency to occur on the side with the higher base line.

\section{ICE BLOGKS}

The ice-block size in ridges has previously been estimated mostly in terms of a long and a short axis and thickness.
The measured thickness in the Baltic Sea has varied from 0.03 to $0.6 \mathrm{~m}$. the long axis averaging $0.60 .9 \mathrm{~m}$ Keinonen, 1977; Kankaanpää, 1988, 1991; Veitch and others, 1991; Leppäranta and Hakala, 1992; Lensu, unpublished). Typically the long axis has been 1.5 times the short-axis length. Another parameter relevant for mass studies has been the ratio of average length to thickness of the ice block. Typical values have been 2.95 4.6. Width, length and area have all seemed to obey lognormal distribution. Similar ice-block studies have been carried out in the Beaufort Sea Tucker and Govoni, 1981; Sayed and Frederking, 1989).

Since the emphasis of previous ice-ridge studies has been on mass, the exact shape of ice blocks has been determined only from photographs, and the number of measured blocks has been quite small. Also, the measurement method has been sensitive to cumulative error in the angles of the main-facet corners Kankaanpää, 1991).

Measurements of the orientation of ice blocks have 
been very rare, and the orientation angle $\psi$ in the plane of the ice-block main facet is always lacking (Kankaanpää, 1991; Carlström, unpublished). Moreover, the method used to determine orientation, with strike and dip as the parameters to be measured, is prone to error when the inclination is small. Also, no attention has been paid to the periodicity of the vertical- and horizontal-orientation Euler angles $\theta$ and $\varphi$ or to the symmetry of the rectangular polyhedrons approximating the ice blocks. Neglecting this effect created overly large standard deviations for the orientation angles.

Calculation of orientational statistics for general threedimensional objects can be accomplished using the methods developed for this purpose (Mardia, 1972). Problems arise when the three-dimensional objects are symmetrical, such as rectangular polyhedrons, in which case their orientation can no longer be described with a single-valued angle triplet $\theta, \varphi$ and $\psi$ having a period of $2 \pi$ Goldstein, 1974). Due to the flatness of the ice blocks, the vertical- and horizontal-orientation angles $\theta$ and $\varphi$ must be treated together, whereas the period for $\psi$ (the orientation angle in the plane of the main facet) can be determined separately. It is natural to assume that the best statistical description of the horizontal and vertical data is obtained when the phases are chosen to that the obtained data set covers as small an area in the $\theta \varphi$-space as possible. A simple iterative algorithm has been found to produce good results with a rather small number of iteration cycles Manninen, unpublished b). The best statistical description for $\psi$ is obtained when the phase values are chosen so as to minimize the standard deviation of the data. Individual $\psi$ values are determined using an algorithm that finds the orientationally best rectangle approximation for the polygonal ice-block main facets (Manninen, unpublished c).

Thus, extensive measurements of ice-block size, shape and orientation were carried out as part of the PIPOR and OSIC projects from 1991 to 1994.

Ice blocks in ridges are more or less flat polyhedrons, whose shape can be described with the number of mainfacet corners $n$, distance $r_{\mathrm{i}}$ between each corner and a fixed point on the main facet, angles $\alpha_{\mathrm{i}}$ between each $r_{\mathrm{i}}$ and a fixed direction on the main-facet plane here the direction perpendicular to the cross-section line between the main-facet and the horizontal plane), thickness $h_{\mathrm{j}}$ of the ice block between two consecutive corners, and corresponding angles $\beta_{\mathrm{j}}$ between the main-facet plane and the side-facet planes (Fig. 8). The orientation is defined by the three Euler angles: vertical rotation $\theta_{\mathrm{m}}$, horizontal rotation $\varphi_{\mathrm{m}}$ and rotation in the main-facet plane, for example angle $\alpha_{1}$ between $r_{1}$ and the direction perpendicular to the cross-section of the main-facet and the horizontal plane (Fig. 9). All these parameters were manually measured in 1991 and 1992. In 1993 and 1994, only the main-facet orientation was measured, to get larger statistics for the most important orientation angles. The highest points of the ice blocks were also surveyed in 1992 in order to reconstruct the three-dimensional geometry of the whole measured part of the ridge. The coordinates of the ice-block corners calculated from these surveys and ice-block measurements are given in the Appendix. Due to poor weather conditions the measurement accuracy was not as good as usual with this

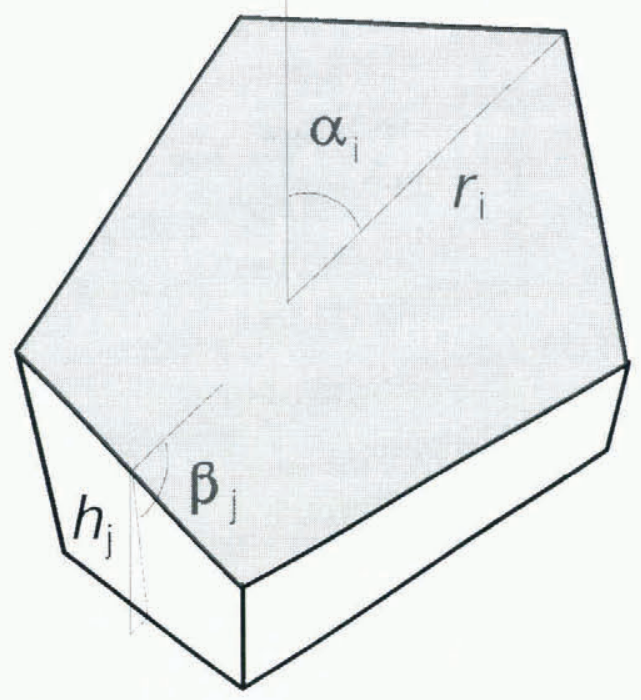

Fig. 8. The dislance $r_{\mathrm{i}}$ between a fixed point on the main facet of an ice block and a corner of the main facel is shown together with the respective angle $\alpha_{\mathrm{i}}$ between $r_{\mathrm{i}}$ and the cross-sectional line of the vertical plane and the main facet that includes the fixed point. The thickness $h_{\mathrm{j}}$ of the ice block in the middle of a main-facel edge is demonstrated together with the corresponding angle $\beta_{\mathrm{j}}$ between the main facet and the side facet. These two paramelers are measured at the intermediate point of the edge joining the corners on eilher side.

technique. The estimated accuracy for the surveyed height is $\pm 0.005 \mathrm{~m}$, for the angle $\pm 2^{\circ}$ and for the

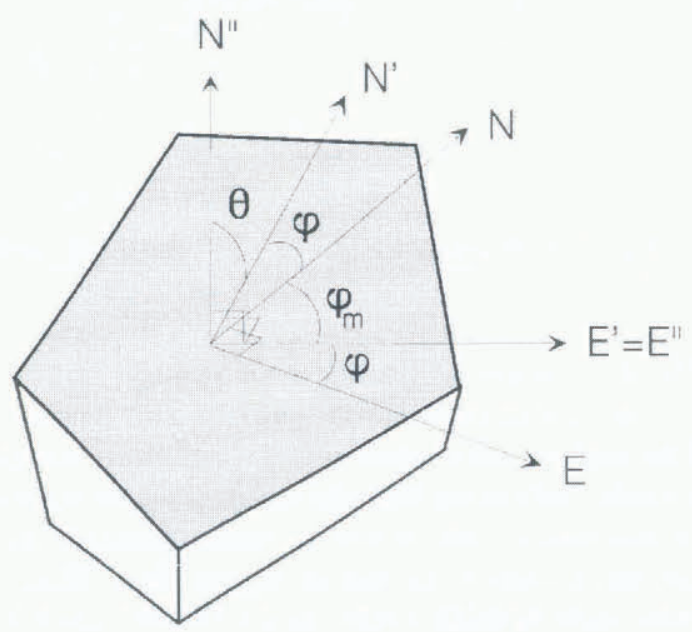

Fig. 9. The Euler angles $\theta$ and $\varphi$ are shown respective to the geographical directions $E$ and N. $E^{\prime \prime}$ is the cross-sectional line between the main facel of the ice block and the horizontal plane. $N^{\prime \prime}$ is the cross-sectional line between the main facet and the vertical plane. The measured horizontal rolation angle $\varphi_{\mathrm{m}}$ is also shown. The sign convention for $\theta$ is such that $\theta$ is negative when the axis on the main facel which defines $\theta$ points upwards. Hence $\theta=-\theta_{\mathrm{m}}$. For modelling purposes $\varphi=0^{\circ}$ corresponds to the axis perpendicular to the ridge-sail direction, and $\varphi$ increases counter-clockwise. Thus $\varphi=180^{\circ}-\varphi_{\mathrm{m}}-\varphi_{\mathrm{vm}}\left( \pm 360^{\circ}\right)$, where $\varphi_{\mathrm{vm}}$ denotes the ridge-sail direction. 
distance $\pm 0.5 \mathrm{~m}$ Manninen 1992, 1993, 1994, unpublished a; Manninen and Rantasuo, unpublished).

For ice-block measurement, first the cross-section between the horizontal plane and the ice-block main facet was checked with a compass having a bubble. This line was marked with an ink pen on the ice block, and its geographical direction was given by the compass. Using the right-angle of the dial plate, the vertical cross-section was drawn on the main facet. The inclinometer was then positioned on this line and the inclination measured. The point at which the horizontal and vertical lines met was used as the reference point for the main-facet shape measurements. The distance to each corner was measured from this point using a tape-measure. The direction angles of these distances were checked with the dial plate, the centre of which was positioned precisely on this reference point. The thickness of the ice block was checked with a scaled clamp, and the angle between the main and side facets with a ruler and protractor. These two parameters were measured roughly in the middle of each side of the main-facet polygon. The measurement precision for the vertical rotation angle $\theta_{\mathrm{m}}$ was $\pm 0.5^{\circ}$, for the horizontal rotation angle $\varphi_{\mathrm{m}} \pm 0.1^{\circ}$, for the angles $\alpha_{\mathrm{i}}$ in the main-facet plane \pm 1.5 , for the radial distance $r_{\mathrm{i}} \pm 0.005 \mathrm{~m}$ and for the side-facet inclination angle $\beta_{\mathrm{j}} \pm 3$. Due to the surface roughness, measurement accuracy for the thickness $h_{\mathrm{j}}$ is not considered better than $\pm 0.01 \mathrm{~m}$, although the measurement precision was $\pm 0.005 \mathrm{~m}$.

The simple mechanical method of measuring ice-block shape and orientation presented here produced data for finding rectangular polyhedrons length $a$, width $b$, thickness $h$ ), which represent the ice blocks in the orientational sense in the best possible way. Statistical calculation of the horizontal and vertical Euler angles $\theta$ and $\varphi$ was carried out with a two-dimensional phaseoptimizing method (Manninen, unpublished b). The third Euler angle $\psi$ and ratio $b / a$ were obtained by orientationally optimizing the matching of the main facet of an ice block with a rectangle Manninen, unpublished c). The period for $\psi$ was also chosen so as to minimize its standard deviation. The dimensions $a$ and $b$ were determined so that $a b$ equalled the main facet area.

The ice-block measurements were carried out in the Bay of Bothnia during 1991 93 and in the Sea of Bothnia in 1994. In February 1991 the measured ice ridge $\left(65^{\circ} 14.3^{\prime} \mathrm{N}, 24^{\circ} 24.4^{\prime} \mathrm{E}\right)$ was new, air temperature was well below $0{ }^{\circ} \mathrm{C}$ and the ice-block edges were still sharp Manninen, 1992, unpublished a). In March 1992 the ridge was newly formed the base was still wet), but the ice field $\left(6525.0^{\prime} \mathrm{N}, 2334.5^{\prime} \mathrm{E}\right)$ was old and had been deformed many times. The ice-block edges were not as sharp as the previous year Fig. 10; Manninen and Rantasuo, unpublished). This ridge was deformed again during the field expedition, and some parameters were remeasured after that. In February 1993 the study area $\left(65^{\circ} 14.9^{\prime} \mathrm{N}, 24^{\circ} 13.9^{\prime} \mathrm{E}\right)$ was also a many times deformed old ice field and the ridge investigated was old. The ice blocks were already rounded by changing weather conditions (Fig. 2; Manninen, 1993). In March 1994 the area of interest $\left(6217.9^{\prime} \mathrm{N}, 20^{\circ} 27.1^{\prime} \mathrm{E}\right)$ was full of netlike rubble with sharp-edged ice blocks (Fig. 3; Manninen, 1994).

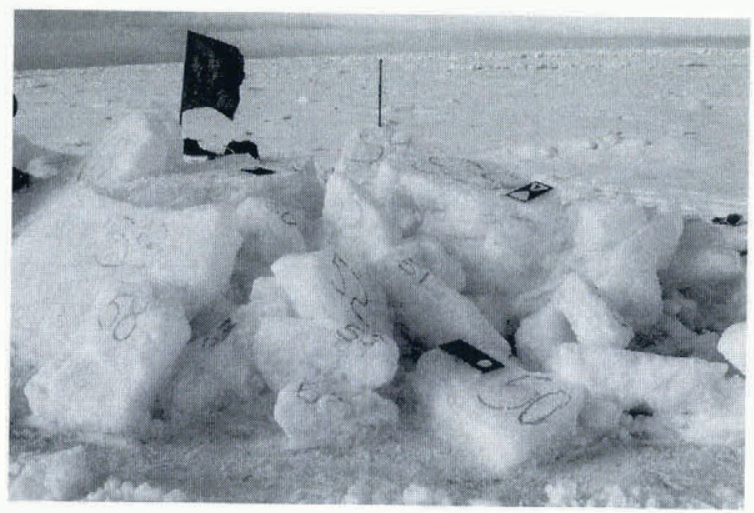

Fig. 10. Individual ice blocks on bolh sides of the sludied ice ridge in the Bay of Bolthia, March 1992 (east side is in fronl). The ridge is fairly new (base nol frozen when measuremenls were starled), but was formed from a consolidated ice field that had deformed many times. The exceptionally mild winter had clearly affected the structure of the ice. Thus, the ridge consisted of old ice allhough the sail structure was new.

The statistics of the measured ice-block parameters (and parameters calculated from them are given in Tables 2 and 3. The complete data are given elsewhere Manninen, 1993, 1994, unpublished a; Manninen and Rantasuo, unpublished). The Lilliefors test for normality and log-normality was used as it gives good results for even small data sets $(n \geq 10)$ (Dudewicz and Mishra, 1988 .

It is remarkable that the average magnitude of the vertical inclination $\theta_{\mathrm{m}}$ and its standard deviation are roughly equal on both sides of the ridge when the number of measured blocks is above 20 on either side. Yet the two sides differ when the orientation of the main facets is described with $\theta$ and $\varphi$ (Table 3 ). Thus, the vertical process of deformation affects both sides in roughly the same way, whereas the horizontal rotation is different.

According to the larger 1993 ice-block data set there is some correlation between the magnitude of the vertical inclination of the ice blocks on both sides of the ridge along the sail direction. Although blocks directly facing each other do not correlate, the general trend is that both sides of the ridge have roughly the same size of vertical inclination angles in the same part of the sail. This is even more obvious when the average values of five successive measurements are examined (Fig. 11). In this case the magnitude of vertical inclination of ice blocks was on average also somewhat greater than the average slope angle (Table 2 ). The packing density of the two sides was almost equal: 51 blocks on the eastern side corresponded to the same ridge-sail length as 49 on the western side.

The number of corners in main facets is very similar in all cases. It is also probable that the ice blocks with the smallest vertical inclination break more than once, as they typically have more main-facet corners than steeply positioned ice blocks. The largest ice blocks tend to have the most corners. Triangles typically have small main facets, and the ratio of side facets to main facets is larger than for polyhedrons with more corners.

Although the shape of the main facet varies widely, the orientation of side facets with respect to the main facet 
Table 2. Average values and respective slandard deviations of the measured vertical-inclination angle $\theta_{\mathrm{m}}$ and the number of corners $n$ of the main facets, the angle between the main-and side-facet planes $\beta_{\mathrm{j}}$ and calculated main-and side-facet areas for the measured ridges and both their sides. Also given is the average ratio of the average tolal side-facel area lo the main facet area, $n<$ sides $\rangle /$ main, but to increase reliability only blocks with at least two measured side facels are included in calculation of the average

\begin{tabular}{|c|c|c|c|c|c|c|c|}
\hline \multirow{2}{*}{$\begin{array}{l}\text { Location of measured ridge, } \\
\text { number of measured blocks }\end{array}$} & \multirow[t]{2}{*}{ Parameter } & \multicolumn{2}{|c|}{ Bolh sides of ridge } & \multicolumn{2}{|c|}{ Western side of ridge } & \multicolumn{2}{|c|}{ Eastern side of ridge } \\
\hline & & Average & S.D. & Average & S.D. & Average & S.D. \\
\hline $\begin{array}{l}\text { Bay of Bothnia, February } 1991 \\
\text { Blocks: } 14(\mathrm{~W})+10(\mathrm{E})=24\end{array}$ & $\begin{array}{l}\theta_{\mathrm{m}} \\
n \\
\beta_{\mathrm{j}} \\
\text { Main-facet area }\left(\mathrm{m}^{2}\right) \\
\text { Side-facet area }\left(\mathrm{m}^{2}\right) \\
n<\text { sides }>\text { main }\end{array}$ & $\begin{array}{l}43.7 \\
4.3 \\
92.7^{\circ} \\
0.476 \\
0.134 \\
2.2\end{array}$ & $\begin{array}{l}17.8 \\
0.9 \\
6.0^{\circ} \\
0.411 \\
0.061 \\
2.6\end{array}$ & $\begin{array}{c}48.2 \\
4.1 \\
93.8 \\
0.359 \\
0.129 \\
2.6\end{array}$ & $\begin{array}{l}19.2 \\
0.6 \\
6.3 \\
0.244 \\
0.045 \\
3.3\end{array}$ & $\begin{array}{c}37.3 \\
4.6 \\
91.2 \\
0.641 \\
0.142 \\
1.6\end{array}$ & $\begin{array}{l}14.3 \\
1.2 \\
5.6 \\
0.542 \\
0.079 \\
1.1\end{array}$ \\
\hline $\begin{array}{l}\text { Bay of Bothnia, March } 1992 \\
\text { Blocks: } 20(\mathrm{~W})+22(\mathrm{E})=42\end{array}$ & $\begin{array}{l}\theta_{\mathrm{m}} \\
n \\
\beta_{\mathrm{j}} \\
\text { Main-facet area }\left(\mathrm{m}^{2}\right) \\
\text { Side-facet area }\left(\mathrm{m}^{2}\right) \\
n<\text { sides }>/ \text { main }\end{array}$ & $\begin{array}{c}47.2 \\
4.3 \\
98.4 \\
0.216 \\
0.090 \\
2.5\end{array}$ & $\begin{array}{l}23.8 \\
1.0 \\
8.4 \\
0.245 \\
0.044 \\
1.7\end{array}$ & $\begin{array}{c}46.8 \\
4.5 \\
101.0^{\circ} \\
0.212 \\
0.099 \\
2.7\end{array}$ & $\begin{array}{l}22.1 \\
0.9 \\
9.2^{\circ} \\
0.185 \\
0.051 \\
1.8\end{array}$ & $\begin{array}{c}47.5 \\
4.0 \\
95.8^{\circ} \\
0.221 \\
0.081 \\
2.3\end{array}$ & $\begin{array}{l}25.8 \\
1.0 \\
6.7^{\circ} \\
0.298 \\
0.035 \\
1.6\end{array}$ \\
\hline $\begin{array}{l}\text { Previous ridge after a new } \\
\text { deformation }\end{array}$ & $\theta_{\mathrm{m}}$ & 45.9 & 21.8 & 45.7 & 20.9 & 46.2 & 23.0 \\
\hline $\begin{array}{l}\text { Bay of Bothnia, February } 1993 \\
\text { Blocks: } 73(W)+73(E)=146\end{array}$ & $\begin{array}{l}\theta_{\mathrm{m}} \\
n\end{array}$ & $\begin{array}{r}37.5 \\
4.3\end{array}$ & $\begin{array}{r}22.5 \\
0.9\end{array}$ & $\begin{array}{r}37.7 \\
4.5\end{array}$ & $\begin{array}{r}22.3 \\
1.1\end{array}$ & $\begin{array}{r}37.4 \\
4.2\end{array}$ & $\begin{array}{r}22.8 \\
0.7\end{array}$ \\
\hline $\begin{array}{l}\text { Sea of Bothnia, March } 1994 \\
\text { Blocks: } 42\end{array}$ & $\theta_{\mathrm{m}}$ & 30.9 & 19.2 & & & & \\
\hline
\end{tabular}

is almost always very close to orthogonal (Table 2). Therefore, approximation of ice-block polygons with rectangular polyhedrons is very good if only the main facets can be closely matched with rectangles. Since triangular facets seem to be rare, it is usually possible to find a tolerably good rectangular approximation for the main ice-block facets (Manninen, unpublished c).

Table 2 indicates that the main facets of ice blocks do not alone represent very well the whole surface of a ridge sail. The average ratio of the average total side-facet area to the main-facet area, $n<$ sides $>/$ main, is on average greater than 2 for blocks in the studied ridges. Only half of the side facets are visible to radar at a given time, but their aerial percentage is roughly as large as that of the main facets. Therefore, it is essential to use threedimensional models for ice ridges. The assumption that the main facets alone represent the ridges well enough is not directly justified.

According to Table 3, either side of an ice ridge can be described by approximating ice blocks with rectangular polyhedrons with normally distributed Euler angles and normally distributed dimensions. A log-normal distribu-

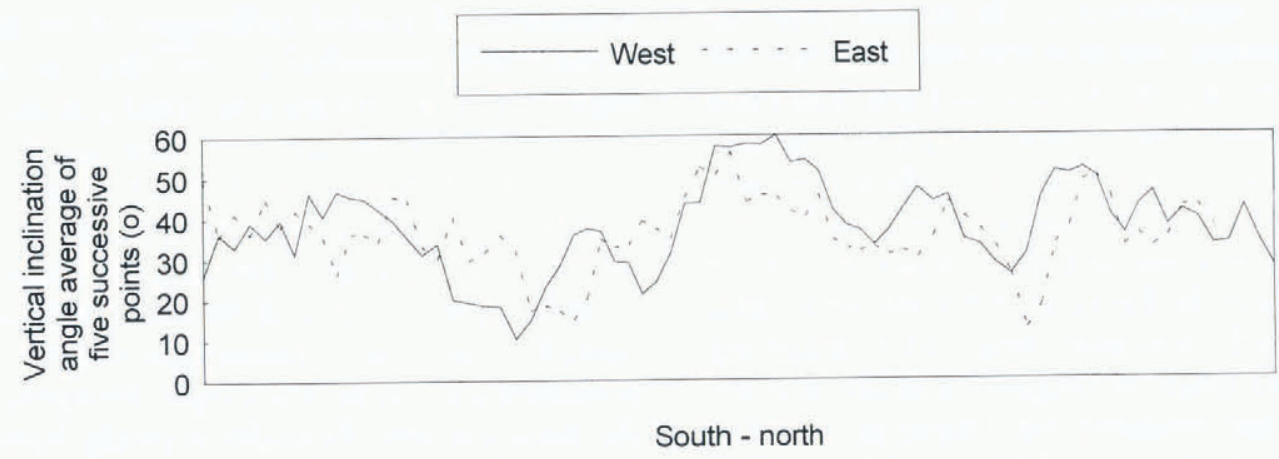

Fig. 11. Average of five consecutively measured vertical-inclination angles of the main facets of ice blocks on both sides of the sludied ridge, along the ridge-sail direction in the Bay of Bothnia, February 1993. The ice blocks on the eastern side have shifted southwards by four blocks. 
Table 3. Mean values and respective standard deviations of the calculated Euler angles $\theta, \varphi$ and $\Psi$ and length $a$, widih $b$ and thickness hof rectangular polyhedrons that best represent the orientation and shape of ice blocks on both sides (west and east) of the measured ridges in the Bay of Bothnia in 1992.94 and in the Sea of Bolhnia in 1994. The dimensionless risk level al which the parameter in question passed the Lilliefors test for normality is also given. Values in brackets correspond to log-normal distribution

\begin{tabular}{|c|c|c|c|c|c|c|c|c|c|c|}
\hline \multirow{2}{*}{$\begin{array}{l}\text { Location of measured ridge, } \\
\text { number of measured blocks }\end{array}$} & \multirow[t]{2}{*}{ Parameler } & \multicolumn{3}{|c|}{ Both sides of ridge } & \multicolumn{3}{|c|}{ Western side of ridge } & \multicolumn{3}{|c|}{ Eastern side of ridge } \\
\hline & & Average & S.D. & $\begin{array}{l}\text { Risk } \\
\text { level }\end{array}$ & Azerage & S.D. & $\begin{array}{l}\text { Risk } \\
\text { level }\end{array}$ & Average & S.I. & $\begin{array}{l}\text { Risk } \\
\text { level }\end{array}$ \\
\hline \multirow{8}{*}{$\begin{array}{l}\text { Bay of Bothnia, } \\
\text { February } 1991 \\
\text { Blocks: } \\
14(\mathrm{~W})+10(\mathrm{E})=24\end{array}$} & $\theta$ & 71.3 & $46.8^{\circ}$ & - & $73.6^{\circ}$ & $44.3^{\circ}$ & 0.10 & $-3.9^{\circ}$ & $41.6^{\circ}$ & 0.05 \\
\hline & $\varphi$ & $14.7^{\circ}$ & $34.6^{\circ}$ & 0.10 & $0.1^{\circ}$ & $26.9^{\circ}$ & 0.10 & $35.1^{\circ}$ & $35.1^{\circ}$ & 0.10 \\
\hline & $\Psi$ & $86.2^{\circ}$ & $35.4^{\circ}$ & 0.10 & $82.9^{\circ}$ & $34.2^{\circ}$ & 0.10 & $88.6^{\circ}$ & 37.3 & 0.10 \\
\hline & $a(\mathrm{~m})$ & 0.852 & 0.371 & 0.10 & 0.782 & 0.336 & 0.10 & 0.949 & 0.412 & 0.10 \\
\hline & & & & $(0.10)$ & & & $(0.10)$ & & & $(0.10)$ \\
\hline & $b(\mathrm{~m})$ & 0.493 & 0.257 & 0.10 & 0.428 & 0.198 & 0.10 & 0.583 & 0.310 & 0.10 \\
\hline & & & & $(0.10)$ & & & $(0.10)$ & & & $(0.10)$ \\
\hline & $h(\mathrm{~m})$ & 0.183 & 0.061 & 0.01 & 0.191 & 0.042 & 0.05 & 0.172 & 0.082 & 0.10 \\
\hline \multirow{8}{*}{$\begin{array}{l}\text { Bay of Bothnia, } \\
\text { March } 1992 \\
\text { Blocks: } \\
20(\mathrm{~W})+22(\mathrm{E})=42\end{array}$} & $\theta$ & 47.2 & $24.0^{\circ}$ & 0.10 & 38.8 & $34.2^{\circ}$ & 0.10 & $56.9^{\circ}$ & $43.6^{\circ}$ & 0.10 \\
\hline & $\varphi$ & $1.9^{\circ}$ & $72.8^{\circ}$ & 0.01 & $-49.4^{\circ}$ & $47.2^{\circ}$ & 0.10 & $-16.9^{\circ}$ & $39.6^{\circ}$ & 0.10 \\
\hline & $\Psi$ & $84.5^{\circ}$ & $44.5^{\circ}$ & 0.10 & $76.1^{\circ}$ & $42.1^{\circ}$ & 0.10 & $66.5^{\circ}$ & 46.2 & 0.10 \\
\hline & $a(\mathrm{~m})$ & 0.605 & 0.271 & 0.05 & 0.618 & 0.276 & 0.10 & 0.594 & 0.274 & 0.01 \\
\hline & & & & $(0.10)$ & & & $(0.10)$ & & & $0.10)$ \\
\hline & $b(\mathrm{~m})$ & 0.348 & 0.214 & 0.05 & 0.360 & 0.167 & 0.10 & 0.338 & 0.252 & 0.10 \\
\hline & & & & $(0.0 .5)$ & & & $(0.01)$ & & & $(0.10)$ \\
\hline & $h(\mathrm{~m})$ & 0.154 & 0.027 & 0.10 & 0.163 & 0.029 & 0.10 & 0.146 & 0.022 & 0.10 \\
\hline \multirow{2}{*}{$\begin{array}{l}\text { Same ridge as previously } \\
\text { after new deformation }\end{array}$} & $\theta$ & $42.4^{\circ}$ & 32.6 & 0.05 & 41.9 & $27.3^{\circ}$ & 0.10 & 60.5 & $41.8^{\circ}$ & 0.10 \\
\hline & $\varphi$ & $38.7^{\circ}$ & $58.8^{\circ}$ & 0.10 & $-36.7^{\circ}$ & 57.8 & 0.10 & $9.0^{\circ}$ & $44.6^{\circ}$ & 0.10 \\
\hline $\begin{array}{l}\text { Bay of Bothnia, February } \\
\text { 1993. Blocks: }\end{array}$ & $\theta$ & $-6.6^{\circ}$ & $42.5^{\circ}$ & 0.01 & $-15.1^{\circ}$ & $41.8^{\circ}$ & 0.10 & $8.7^{\circ}$ & 41.4 & 0.10 \\
\hline $74(\mathrm{~W})+74(\mathrm{E})=148$ & $\varphi$ & $16.4^{\circ}$ & $42.9^{\circ}$ & 0.10 & 12.4 & $41.3^{\circ}$ & 0.10 & $17.9^{\circ}$ & 45.1 & 0.10 \\
\hline \multirow{2}{*}{$\begin{array}{l}\text { Sea of Bothnia, March } \\
\text { 1994. Blocks: } 42\end{array}$} & $\theta$ & $7.1^{\circ}$ & $36.0^{\circ}$ & 0.10 & & & & & & \\
\hline & $\varphi$ & $39.4^{\circ}$ & 46.2 & 0.10 & & & & & & \\
\hline
\end{tabular}

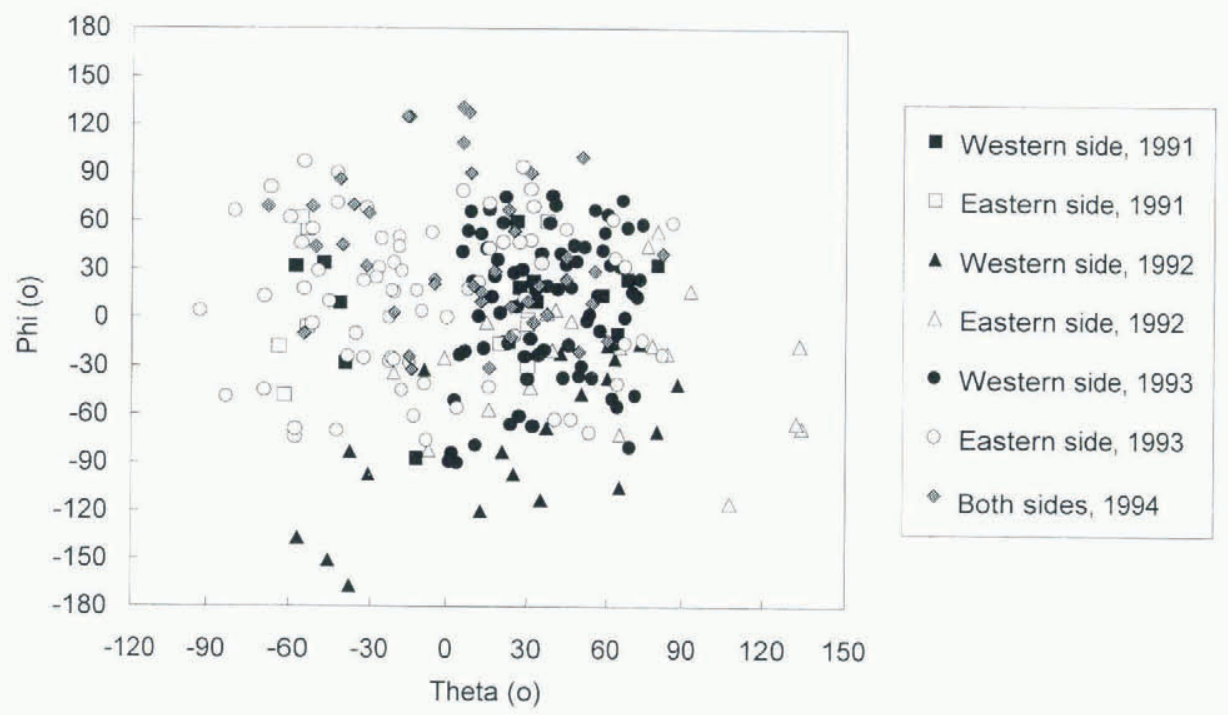

Fig. 12. Correlation of the vertical $\theta$ and horizontal $\varphi$ Euler angles of the main facets of the ice blocks on both sides of the ridges studied in the Bay of Bothnia and in the Sea of Bothnia. 


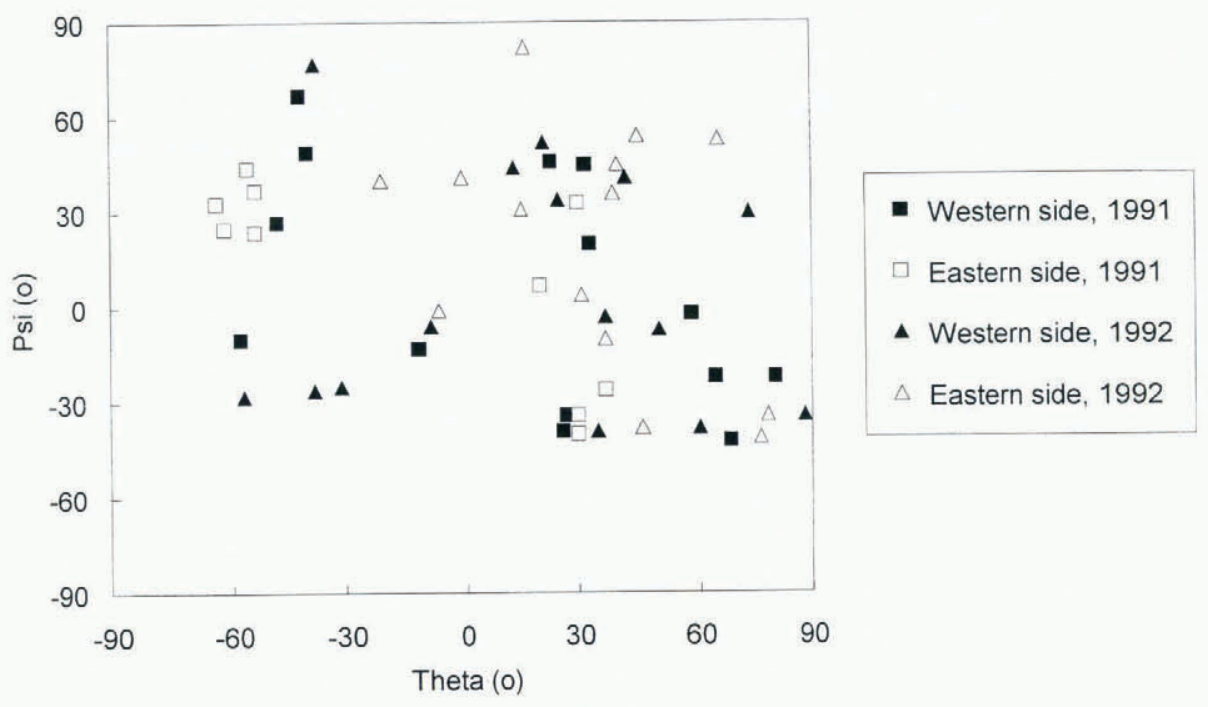

Fig. 13. Correlation of Euler angles $\varphi$ and $\Psi$ in the horizontal and main-facet plane of the main facets of the ice blocks on both sides of the ridges studied in the Bay of Bothnia.

tion could equally well be used for the width and length of the main facet, but the difference is small, as the standard deviations are so large. However, it should be noted that $a$ and $b$ are fictive dimensions that optimize the orientational approximation. Therefore, it is hardly surprising that the log-normal distribution found to fit well the commonly used long and short axes is not distinctly better for $a$ and $b$ than the normal distribution. Surprisingly, the average thickness of ice blocks $h$ does not always pass the test for normality very well, but this is probably due to ice blocks comprising several ice layers. The vertical Euler angle $\theta$ of the whole ridge obviously deviates from a Gaussian distribution. The typical vertical-inclination value definitely depends on the side of the ridge, which is understandable considering the formation process of an ice ridge. Clearly the two sides of a ridge should be treated statistically separately.

There is virtually no correlation between the six parameters defining size, shape and orientation of the rectangular polyhedrons approximating the ice blocks. Only the length $a$ and width $b$ have a slight inter- dependence (Figs 12-14). Numerous ice-block main facets can be approximated with almost square rectangles.

Definitions of the ice-block length $l$ and width $b$ measured in the Beaufort Sea are not identical to those of $a$ and $b$ used in this paper (Tucker and Govoni, 1981; Sayed and Frederking, 1989). However, it is interesting to note that the regression equations for the relationship of dimensions obtained in the Beaufort Sea also reasonably apply to the data presented here. The two equations found to describe well the relationship between the iceblock length $l$ and thickness $h$ in the Beaufort Sea are $l=0.32 \pm 2.328 h$ and $l=2.38 \sqrt{h}$ (Sayed and Frederking, 1989). Average values of ice-block length $a$ in this paper usually fall between the values obtained using these two equations and the average ice-block thickness $h$ (Table 3). The linear relationship produces mostly values closer to the observed ones. Also the interdependence of ice-block width $b$ and length $a$ in the Baltic Sea is reasonably close to that in the Beaufort Sea, but the correlation coefficient for the linear regression is only 0.45

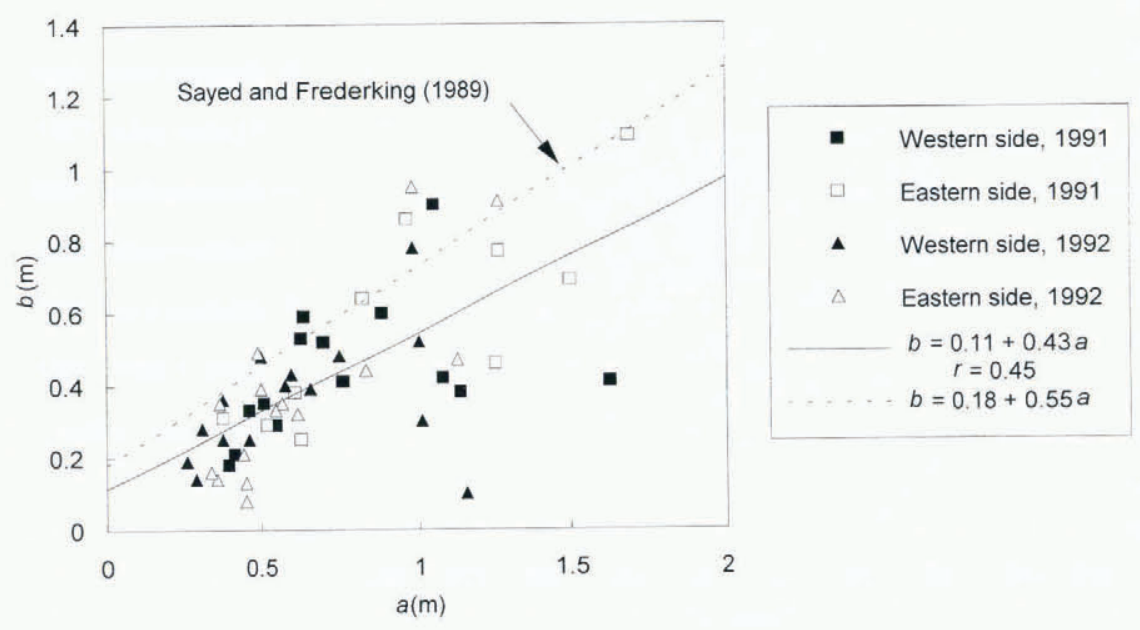

Fig. 14. Correlation of the length $a$ and width $b$ of the rectangular polyhedrons orientationally best approximating the ice blocks on both sides of the ridges studied in the Bay of Bothnia in 1991 and 1992. 


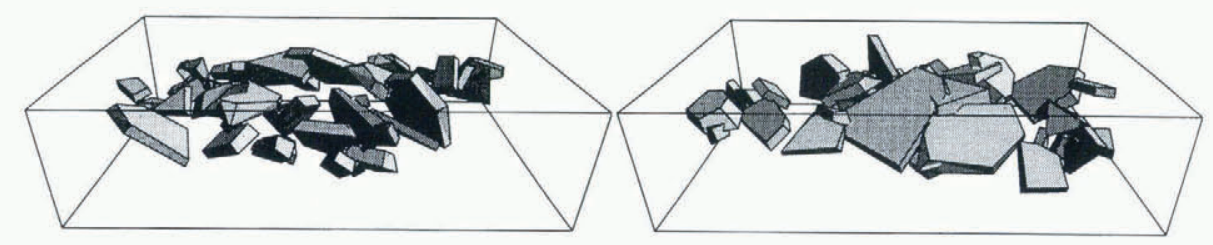

West

East

Fig. 15. General surface structure of the studied ice-ridge sail in the Bay of Bothnia in 1992 before fresh deformation of the ice field. The direction of the observation point is given for all images.

Fig. 14). Most of the largest deviations from the regression line are caused by triangular main facets as shown elsewhere (Manninen, unpublished c).

The ice-block main-facet areas reported in this paper were calculated taking into account the individual polygonal shapes of the ice-block main facets. Usually the main-facet area has been approximated from the measured ice-block length and width. The main-facet area has been found in the Beaufort Sea to depend on the ice-block thickness. Two equations are given by Tucker and Govoni 1981 ) to describe this relationship, namely $A=0.67 \exp (1.86 h)$ and $A=4.48 h^{2}$. The average iceblock main-facet areas observed in the Baltic Sea Table 2 were found to be between the corresponding values obtained using these two equations and the empirical average ice-block thickness values (Table 3). The thickness-squared relationship produces values closer to the empirical ones. The data set of Tucker and Govoni deviated from the square relationship especially in lower thickness categories. The determination of an ice-block main-facet area from measurement of the actual mainfacet polygon is certainly more precise than estimating it from the approximate length and width. Therefore, it is porbable that the ice-block main-facet area values obtained in the Baltic Sea are more accurate than those obtained in the Beaufort Sea. This may explain why the Baltic Sea ice measurements better obey the physically justified square law than the Beaufort Sea measurements of ice blocks of equal size.

The general structure of the ice ridge studied in 1992 in shown in Figure 15 as it was before fresh deformation of the ice field. The average vertical inclination on either side of the ridge increased somewhat upon new deformation. Also the surveyed heights increased in general during the deformation process. This is natural as the pressing force made the ridge narrower. Although the part of the sail next to the measured blocks was destroved completely, the change in the measured part was moderate. Before deformation of the ice field the direction of the ridge sail was $300^{\circ}$ and $182^{\circ}$ in opposite directions from one point along the sail, compared with $339^{\circ}$ and $176^{\circ}$, respectively, after deformation. Thus the ridge rotated horizontally more or less as a solid mass, with only a few blocks deviating distinctly from the main trend. The greatest change seems to have occurred for ice blocks near the middle height of the ridge sail.

In 1994 the ice field in the Sea of Bothnia was deformed everywhere in net-like fashion. There were no clear linear ridge sails, each mesh being surrounded by deformed ice. Thus the orientation of ice blocks was measured without any attempt to distinguish between the two sides of the sails. As Tables 2 and 3 show, the orientation of ice blocks could be described reliably with a normal distribution.

\section{INCIDENCE-ANGLE DISTRIBUTION OF AN ICE-RIDGE SAIL}

A radar sees an ice ridge as a heap of discrete scatterers with individual incidence angles. When the scatterers (here separate ice-block facets) are smaller than the radar image resolution as is the case for airborne and satellite SARs in the Baltic Sea), each pixel is correlated to an average over backscattering coefficients corresponding to the individual incidence angles. Thus, it is essential to know the orientations of the ice blocks with respect to the radar. This can be statistically described with incidenceangle distributions of ice ridges, which have been calculated for measured ridges using a previously developed three-dimensional geometrical model for the surface layer of the sail of an ice ridge Manninen, 1992). The incidence-angle distributions of the three facet types of the rectangular polyhedrons approximating the ice blocks are shown in Figure 16 for either side of the ridge measured in the Bay of Bothnia in 1992 (Table 3; Fig. 10). Calculations were performed using the radar incidence angle of ERS-I SAR (23).

Naturally, incidence angles tend to be larger on the distal than on the proximal side. Also, part of the distal side is shaded, as the slope of the sail is very steep compared with the radar incidence angle. Obviously on either side the curve is smoothest, as the radar is looking from the direction of the average horizontal rotation angle of the ice-block main facets $\varphi$. There is a clear peak in the incidence-angle distribution of the main facets close to the radar incidence angle of 23 . because the orientation-angle distributions are so broad. Similarly there is a corresponding small peak in the incidence-angle distributions of the side facets $b h$ at about 90-23, since the vertical inclination of these facets resembles that of the main facets (Fig. 10). Because the statistical distributions of the orientation angles and the dimensions were so broad, there is no major difference between the two sides of the ridge or the azimuthal-facing directions. The average incidence-angle distributions combining main and side facets and various azimuthal-looking directions for either side of the ridge sail are shown in Figure 17. Also ridges with other parameter values have produced very similar incidence-angle distributions Manninen, 


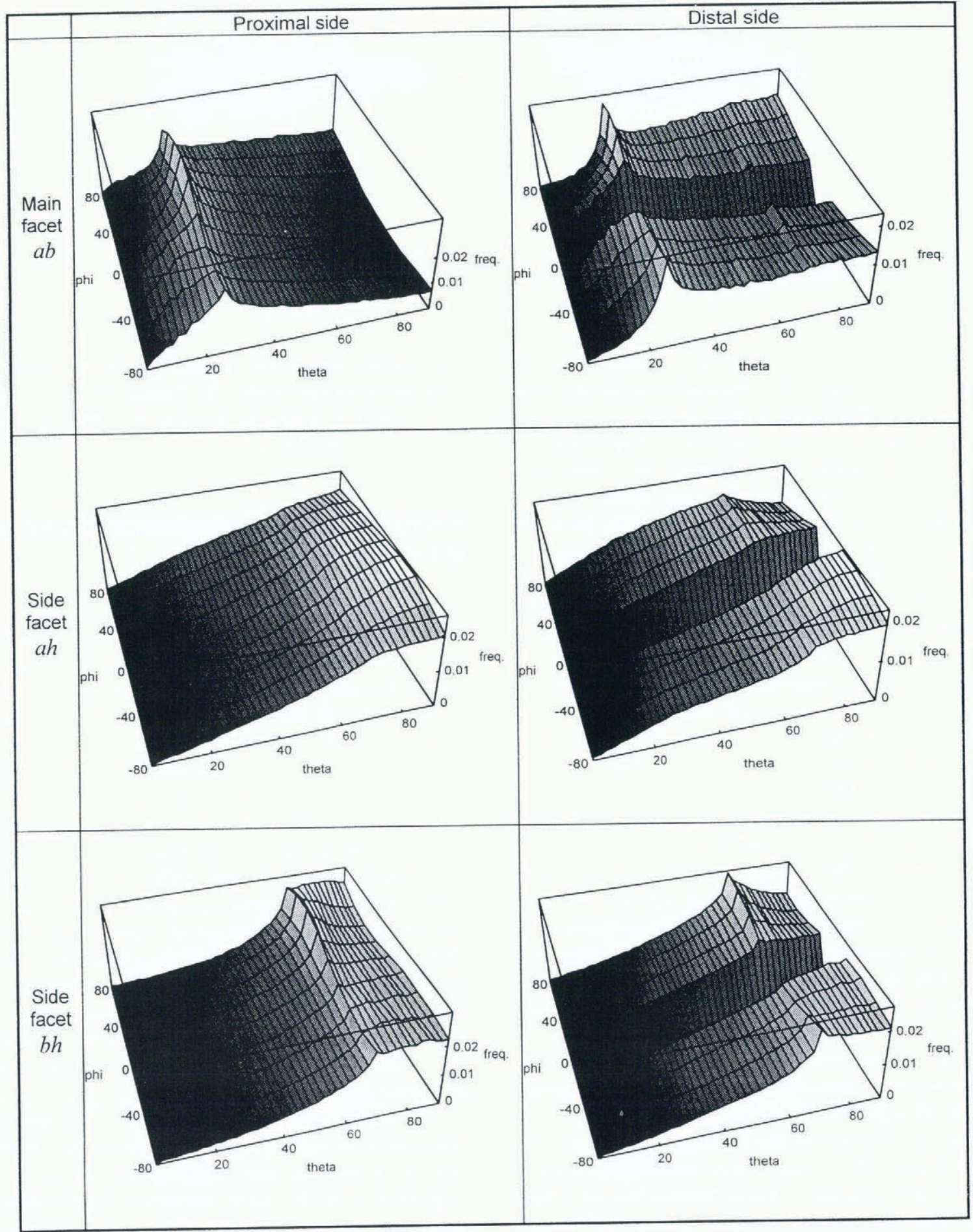

Fig. 16. Incidence-angle distribution for ice-block facets $a b$, ah and bh on either side of the ice ridge. The SAR parameters are those of ERS-1: frequency $5.3 \mathrm{GHz}$, radar incidence angle $23^{\circ}$. The curves have been calculated for $\varphi$ values from $80^{\circ}$ $1080^{\circ}$ with an increment of $20^{\circ}$ to show the entire azimuthal variation. The distal side is shaded by the sail when $\varphi$ is $0^{\circ}$.

1992). Thus, ridges in general seem to be very similar from the point of view of radars. Although the radar incidence angle dominates the local incidence-angle distributions of ridges, and the azimuthal-looking direction also has a clear effect, these features are somewhat similar for all ridges and do not depend very much on the exact geometrical shape of the ridges. This result is supported by numerous calculations of simulated ridges.

Incidence-angle distributions can be used to check whether the diffraction effect of the specular reflection is larger than the first-order backscattering. For the specular component the following equation was used
(Ulaby and others, 1982):

$$
\begin{aligned}
\sigma^{0}\left(\theta_{i}\right)= & \frac{k^{2}}{\pi}\left|R_{0}\right|^{2}\left|\cos ^{2} \theta_{i}\right| d_{i} h_{i} \mathrm{e}^{-\left(2 k \sigma \cos \theta_{i}\right)^{2}} \\
& \cdot\left(\frac{\sin \left(h_{i} k \sin \theta_{i} \cos \varphi_{i}\right)}{h_{i} k \sin \theta_{i} \cos \varphi_{i}}\right) \\
& \cdot\left(\frac{\sin \left(d_{i} k \sin \theta_{i} \sin \varphi_{i}\right)}{d_{i} k \sin \theta_{i} \sin \varphi_{i}}\right)^{2}, \quad i=1,2,3
\end{aligned}
$$

where $d_{1}=d_{2}=h, d_{3}=l_{1}=b, l_{2}=l_{3}=a, R_{0}$ is the Fresnel reflection coefficient for $\mathrm{VV}$ or $\mathrm{HH}$ polarization, $\varphi_{i}$ is the azimuthal angle between the incoming radar- 


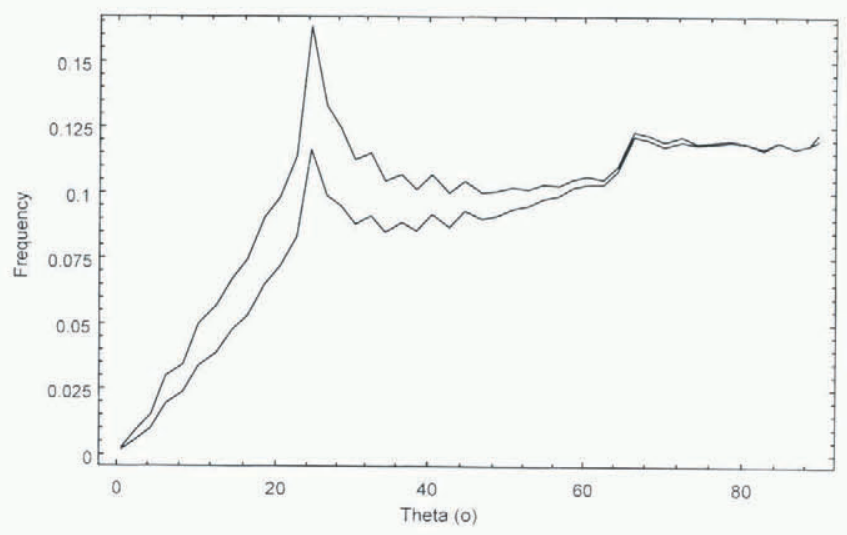

Fig. 17. Incidence-angle distribution averaged over the whole proximal and distal side. The cumulative distribution of the distal side does not reach unity, as part of the dislal side is shaded, causing no backscattering.

wave vector and the side $l_{i}$, and $\sigma$ is the rms height of the surface roughness. Since strict calculation would require integration over both $\varphi_{i}$ and $\theta_{i}$, the calculations have been simplified. Small values of $\theta_{i}$ dominate the specular component so that its value falls off rapidly with increasing $\theta_{i}$ (Fig. 18). Moreover, the effect of $\varphi_{i}$ is small for small values of $\theta_{i}$ (Fig. 19). Therefore, it suffices to calculate the specular component using only one value for $\varphi_{i}$. Zero was selected for use in these calculations. At first, the value of the specular component was calculated for $\theta_{i}$ from zero to $90^{\circ}$ in increments of $0.1^{\circ}$. These values were then weighted with the corresponding incidenceangle distributions, ice-block facet areas and sail slopes on each side of the ridge and finally added together (Manninen, 1992). For comparison the first-order backscattering component for the same incidence-angle distribution was calculated using an integral equation method (IE.M; Fung, 1994).

The first-order IEM backscattering component turned out to be $7-12 \mathrm{~dB}$ larger than the specular component for the incidence-angle distribution examined. Also in

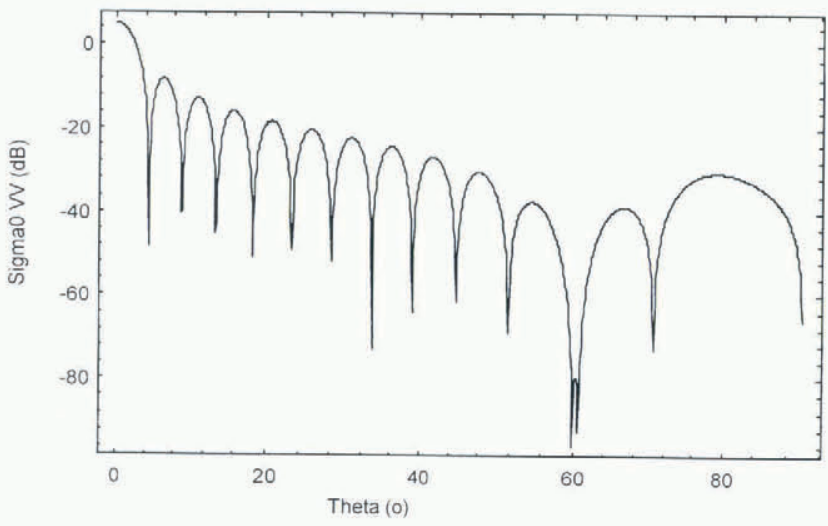

Fig. 18. Specular reflection as a function of local vertical incidence angle $\theta$ for $\mathrm{V} \mathrm{V}$ polarization and $5.3 \mathrm{GHz}$ and the ridge studied in the Bay of Bothnia in 1992.

previous studies the specular component has been modest Manninen, 1992). However, calculation of the specular component is numerically very demanding, since the function in question is so steeply peaked. On the other hand, the incidence-angle distributions of this paper have been calculated with a rather coarse increment of 2 in $\theta, \varphi$ and $\psi$. Thus, the abundance of the smallest local incidence angles cannot be guaranteed with high precision. It is difficult to estimate how much this could affect calculation of the specular component, but so far the firstorder backscattering seems to be more important. If this is the case, the ridges should be visible in SAR images basically the same way within a broad frequency band. However, the situation is complicated by the change in the proportions of surface and volume backscattering with changing frequency.

\section{CONCLUSIONS}

The results obtained here confirm that geometrical properties of the two sides of the Baltic Sea ridges are not generally equal. The average slope angle of both

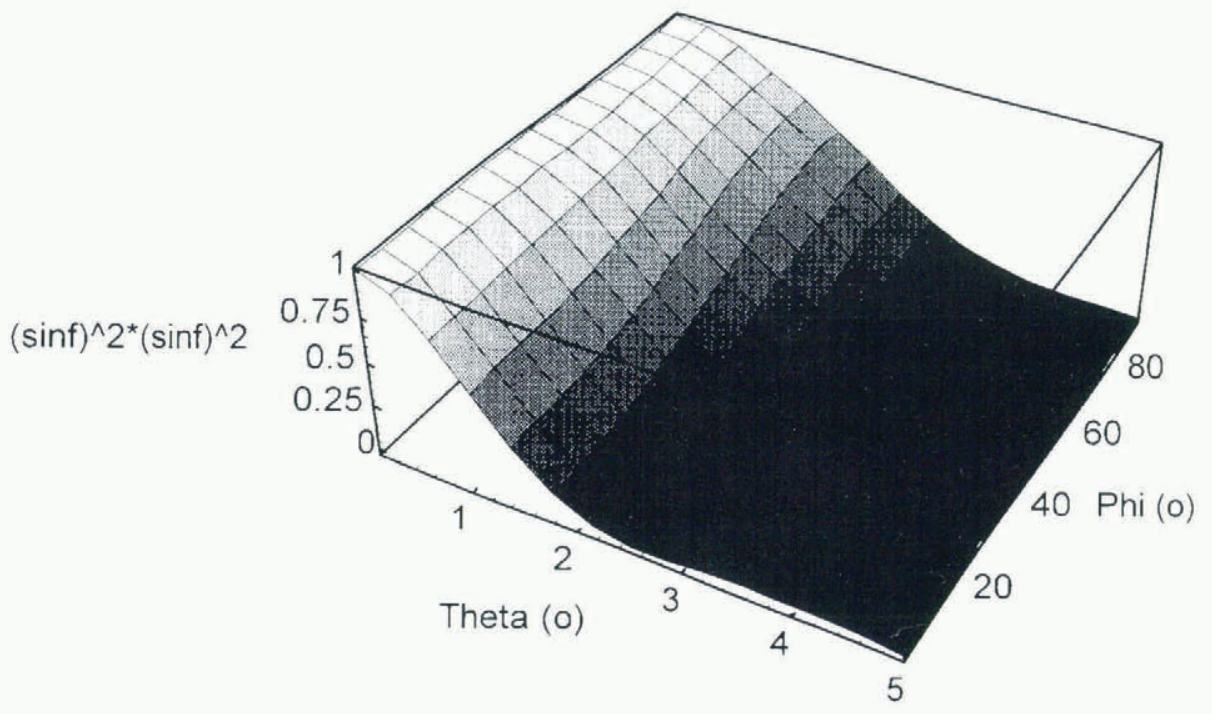

Fig. 19. The azimuthal component $\left(\sin \left(h_{i} k \sin \theta_{i} \cos \varphi_{i}\right) / h_{i} k \sin \theta_{i} \cos \varphi_{i}\right)^{2} \times\left(\sin \left(d_{i} k \sin \theta_{i} \sin \varphi_{i}\right) / d_{i} k \sin \theta_{i} \sin \varphi_{i}\right)^{2}$ of the specular reflection (Equation (1)) as a function of local vertical incidence angle $\theta$ and azimulhal incidence angle $\varphi$ for VV polarization and $5.3 \mathrm{GHz}$ and the main facets of the proximal side of the vidge sludied in the Bay of Bothnia in 1992. 
sides, however, seems to approach the same value statistically with increasing measurement distance. A slight negative correlation between the slope angle and width is typical. The magnitude of the vertical inclination of ice-block main facets correlated to some extent on the two sides of a ridge.

All three orientation and all three size parameters of ice blocks on both sides of the ridges studied can be considered as normally distributed, although a $\log$ normal distribution fits slightly better the width and length of the fictive rectangle approximating the main ice-block facet. There is almost no correlation between any two of these six variables. Only the width and length of the main-facet rectangle have a vague positive interdependence. Three-dimensional modelling of ice ridges is essential, since the total side-facet area visible is typically at least as large as the total main-facet area.

The incidence-angle distributions of ridges generally tend to be very similar, although the ridge parameters differ. This is mainly due to the fact that Euler angles describing the ice-block orientations tend to have broad distributions, with a standard deviation of approximately $40^{\circ}$. The first-order term of surface backscattering of ridges seems to be dominant, but the numerical inaccuracy does not permit very definite opinions.

\section{ACKNOWLEDGEMENTS}

The author is grateful to M. Rantasuo from VTT Automation, Space Technology for his cooperation with the measurements performed in 1991 and 1992. Cooperation with Dr E. Aldworth from the Scott Polar Research Institute, Cambridge, U.K., is also gratefully acknowledged. The author wishes to thank H. Söderman for his assistance in measuring ridge-sail slopes in 1993. The principal investigators of the two ERS-1 pilot projects, Dr M. Leppäranta and H. Grönvall Phil. Lic., deserve many thanks for their support, and the latter also for successful route-planning during the field expeditions in 1993 and 1994. The author wishes to thank the crew of R/V Aranda, helicopter pilots and other participants in the field expeditions for their excellent cooperation. This work was financially supported by the Finnish Board of Navigation and TEKES.

\section{REFERENCES}

Carlström, A., ed. Unpublished. Baltic experiment for ERS-1. Gothenburg, Chalmers University of Technology. Department of Radio and Space Science. (Internal Report RSG 1994-2.)

Dudewicz, E.J. and S.N. Mishra. 1988. Modern mathematical statistics. Singapore, etc., John Wiley and Sons.

Fung, A.K. 1994. Microwave scaltering and emission models and their applications. Norwood, MA. Artech House.

Goldstein, H. 1974. Classical mechanics, Reading, MA, Addison-Wesley.

Grönvall, H. and A. Seinä. 1994. The operational sea ice charting using ERS-1 images in the Baltic Sea. In Proceedings, ERS-1 Pilot Project Workshop, June 1994, Toledo, 149-152.

Kankaanpää, P. 1988. Morphology of a Baltic Sea ice pressure ridge. Geophysica, $24(1-2), 15-33$.

Kankaanpää, P. 1989. Structure of first year pressure ridges in the Baltic Sea. In Axelsson, K. B. E. and L. A. Fransson, eds. PO.AC 89. The 10th International Conference on Port and Ocean Engineering under Arctic Conditions, Jume 12-16 1989, Luleä, Sweden. Proceedings. Vol. 1. Luleå, Tekniska Högskolan i Luleå, 87-102
Kankaanpää, P. 1991. Morphology of sea ice pressure ridges in the Baltic Sea. (Licenciate thesis, University of Helsinki.

Keinonen, A. 1976. The shape and size of ice ridges in the Baltic according to measurements and calculations. Styrelsen för Vintersjöfartsforskning/Winter. Nazigation Research Board. Research Report 17.

Keinonen, A. 1977. Measurements of physical characteristics of ridges on April 14 and 15, 1977. Styrelsen för Vintersjöfartsforskning/Winter Vavigation Research Board. Research Report 22.

Lensu, M. Unpublished. Statistics of a ridged ice field in the Bay of Bothnia. Helsinki, Finnish Institute of Marine Research. Internal report 1993-11.)

Leppäranta, M. and R. Hakala. 1992. The structure and strength of lirst-year ice ridges in the Baltic Sea. Cold Reg. Sri. Technol., 203 , $295-311$.

Leppäranta, M., J. E. Lewis and H. B. Granberg. 1990. The occurrence and size of ice ridges in the Baltic Sea, In IAHR 90. The 10th International Symposium on Lee, August 20-23 1990. Espoo. Finland. Proceedings. Vol. 1. Espoo, Helsinki University of Technology, 314 323.

Leppäranta. M. and 7 others. 1993. Finnish ERS-1 Baltic Sea ice experiment in winter 1992. In Kaldeich, B., ed. Proceedings of the Fïrst ERS-1 Symposium; Space at the Service of our Environment, 46 November 1992. Cannes, France. Vol. 1. Paris, European Space Agency, 307312. (ESA SP-359.)

Manninen, A. T. 1992. Effects of ice ridge properties on calculated surface backscattering in BEPERS-88. Int. J. Remote Sensing, 13 (13), 24692487.

Manninen, A.T. 1993. Statistical calculations of 3D-orientation parameters of flat symmetrical polyhedrons. Pattern Recognition Lell., 14, $207-211$.

Manninen, A.T. 1994. Orientational approximation of convex polygons with rectangles. Paltern Recognition Lell., 15. $677-682$.

Manninen, A.T. Unpublished a. Mechanical sea ice topography measurements in the Bay of Bolhnia during 6-12 February 1991. Helsinki, Finnish Institute of Marine Research. (Internal report 1992-1.)

Manninen, A.T. Unpublished b. Mechanical measurements of sea ice surface topography. Helsinki, Finnish Institute of Marine Research. Internal report 1993-8.

Manninen, A.T. Unpublished c. Large and small scale sea ice surface topography measurements during 1428 March. 1994. Helsinki, Finnish Institute of Marine Research. Internal report 1994-12.

Manninen, A. T. and M. Rantasuo. Unpublished. Sea ice surface topography measurements. Helsinki, Finnish Institute of Marine Research. Internal report 1993-2.)

Mardia, K. V. 1972. Statistics of directional data. New York and London, Academic Press.

Palosuo, E. 1974. The formation and structure of ice ridges in the Baltic. Styrelsen för Vintersjofartsforskning Winter Navigation Research Board. Research Report 12.

Sayed, M. and R. M. W. Frederking. 1989. Measurements of ridge sails in the Beaufort Sea. Can. J. Cinil Eng., 16 1), 16 21.

Tucker, W. B., III and J. W. Govoni. 1981. Morphological investigations of first-year sea ice pressure ridge sails. Cold Reg. Sci. Technol., 5 1), 1-12.

Ulaby, F.T., R. K. Moore and A. K. Fung. 1982. Microwave remole sensing: active and passive. Fol. 2. Reading, MA, Addison-Wesley Publishing Company.

Veitch, B., M. Lensu, K. Riska, P. Kosloff, P. Keiley and P. Kujala. 1991. Field observations of ridges in the northern Baltic Sea. In Muggeridge, D. B., D. B. Colbourne and H. M. Muggeridge, eds. POAC'91. The Illh International Conference on Port and Ocean Engineering under Arctic Conditions, September 2428 1991, St. John's, Canada. Proceedings. Vol. 1. St. John's, Memorial University of Newfoundland. Ocean Engineering Research Centre, 381-400. 


\section{APPENDIX}

Coordinates of ice-block corners from the datum point used for surveving when measuring the ridge in the Bay of Bothnia in

March 1992. The western side was marked in blue and the eastern side in red (Figs 10 and 15)

\begin{tabular}{|c|c|c|c|c|c|c|c|c|c|c|c|c|c|}
\hline \multirow[t]{2}{*}{ Block } & \multicolumn{3}{|c|}{ Top main facel } & \multicolumn{3}{|c|}{ Boltom main facet } & \multirow[t]{2}{*}{ Block } & \multicolumn{3}{|c|}{ Top main facel } & \multicolumn{3}{|c|}{ Bottom main facet } \\
\hline & $x(\mathrm{~m})$ & $y(\mathrm{~m})$ & $z(\mathrm{~m})$ & $x(\mathrm{~m})$ & $y(\mathrm{~m})$ & $z(\mathrm{~m})$ & & $x(\mathrm{~m})$ & $y(\mathrm{~m})$ & $z(\mathrm{~m})$ & $x(\mathrm{~m})$ & $y(\mathrm{~m})$ & $z(\mathrm{~m})$ \\
\hline \multirow{5}{*}{ blue 51} & 4.080 & 2.452 & 0.700 & 4.072 & 2.598 & 0.603 & \multirow{5}{*}{ blue 62} & 3.459 & 0.064 & 0.496 & 3.268 & 0.117 & 0.381 \\
\hline & 4.481 & 2.297 & 0.470 & 4.508 & 2.428 & 0.302 & & 4.185 & 0.025 & 0.394 & 3.984 & 0.151 & 0.344 \\
\hline & 4.571 & 1.747 & 0.064 & 4.561 & 1.806 & 0.055 & & 4.222 & -0.108 & 0.173 & 4.02 & -0.01 & 0.093 \\
\hline & 3.656 & 1.456 & 0.144 & 3.626 & 1.503 & 0.054 & & 4.102 & -0.783 & 0.019 & 3.882 & -0.801 & -0.109 \\
\hline & 3.719 & 2.146 & 0.600 & 3.673 & 2.224 & 0.493 & & 3.91 & -0.974 & 0.475 & 3.679 & -0.942 & 0.414 \\
\hline \multirow{4}{*}{ blue 52} & 4.592 & $\begin{array}{l}2.227 \\
2.371\end{array}$ & $\begin{array}{l}0.707 \\
0.670\end{array}$ & 4.606 & 2.200 & 0.605 & \multirow{4}{*}{ blue 63} & 3.445 & -0.446 & 0.404 & 3.293 & 0.381 & 0.354 \\
\hline & 4.402 & $\begin{array}{l}2.371 \\
2.761\end{array}$ & 0.670 & 4.429 & 2.362 & 0.543 & & 3.586 & 0.313 & 0.25 & 3.459 & -0.227 & 0.172 \\
\hline & 4.827 & 2.761 & 0.697 & 4.852 & 2.760 & 0.559 & & 3.587 & -0.512 & 0.097 & 3.46 & -0.459 & -0.008 \\
\hline & 4.867 & 2.470 & 0.726 & 4.902 & 2.466 & 0.610 & & 3.445 & 0.639 & 0.256 & 3.293 & -0.608 & 0.179 \\
\hline \multirow{5}{*}{ blue 53} & $\begin{array}{l}4.627 \\
4.412\end{array}$ & & $\begin{array}{l}0.812 \\
0.691\end{array}$ & $\begin{array}{l}4.722 \\
4.426\end{array}$ & $\begin{array}{l}0.805 \\
0.299\end{array}$ & $\begin{array}{l}0.664 \\
0.600\end{array}$ & \multirow{5}{*}{ blue 64} & 3.659 & 0.581 & 0.343 & 3.521 & -0.493 & 0.245 \\
\hline & $\begin{array}{l}4.412 \\
4.246\end{array}$ & $\begin{array}{l}0.299 \\
0.333\end{array}$ & $\begin{array}{l}0.691 \\
0.680\end{array}$ & $\begin{array}{l}4.426 \\
4.256\end{array}$ & $\begin{array}{l}0.299 \\
0.342\end{array}$ & $\begin{array}{l}0.600 \\
0.570\end{array}$ & & 3.911 & -0.551 & 0.139 & 3.818 & -0.47 & -0.006 \\
\hline & $\begin{array}{l}4.246 \\
4.018\end{array}$ & 0.836 & $\begin{array}{l}0.680 \\
0.758\end{array}$ & 3.829 & 0.912 & $\begin{array}{l}0.570 \\
0.507\end{array}$ & & 3.926 & 0.959 & 0 & 3.831 & -0.942 & 0.169 \\
\hline & $\begin{array}{l}4.018 \\
4.000\end{array}$ & 1.048 & 0.799 & 4.002 & 1.109 & $\begin{array}{l}0.507 \\
0.586\end{array}$ & & 3.536 & -1.098 & 0.288 & 3.341 & -1.134 & 0.159 \\
\hline & $\begin{array}{l}4.000 \\
4.332\end{array}$ & 1.218 & 0.870 & 4.344 & 1.241 & $\begin{array}{l}0.586 \\
0.763\end{array}$ & & 3.464 & 0.98 & 0.385 & 3.316 & -0.942 & 0.239 \\
\hline \multirow{6}{*}{ blue 54} & 4.098 & 1.299 & 0.864 & 3.781 & 1.291 & 0.704 & \multirow{4}{*}{ blue 65} & 4.532 & 0.481 & 0.723 & 4.517 & -0.377 & 0.726 \\
\hline & 4.223 & 1.474 & 0.660 & 4.062 & 1.499 & $\begin{array}{l}0 . / 04 \\
0.484\end{array}$ & & 4.645 & -0.479 & 0.49 & 4.623 & 0.344 & 0.471 \\
\hline & 4.503 & 1.416 & 0.443 & 4.452 & 1.410 & 0.326 & & 4.151 & -0.844 & -0.377 & 4.086 & -0.695 & 0.436 \\
\hline & 4.754 & 1.082 & 0.398 & 4.607 & 0.977 & 0.182 & & 3.201 & -0.978 & 0.935 & 3.13 & 0.826 & 0.91 \\
\hline & 4.280 & 0.862 & 0.936 & 4.200 & 0.707 & 0.960 & \multirow{2}{*}{ blue 66} & 4.662 & -0.459 & 0.479 & 4.55 & 0.466 & 0.362 \\
\hline & 4.180 & 0.966 & 0.970 & 4.083 & 0.894 & 0.965 & & 4.844 & 0.425 & 0.334 & 4.754 & -0.425 & 0.206 \\
\hline \multirow{4}{*}{ blue 55} & 4.126 & 0.885 & 0.515 & 4.135 & 0.801 & 0.416 & & 4.988 & -0.752 & 0.292 & 4.925 & 0.795 & 0.158 \\
\hline & 4.179 & 1.145 & 0.321 & 4.192 & 1.061 & 0.203 & & 4.584 & -0.841 & 0.615 & 4.451 & -0.894 & 0.51 \\
\hline & 4.314 & 1.075 & 0.391 & 4.325 & 0.975 & 0.267 & blue 67 & 4.228 & 0.846 & 0.341 & 4.142 & -0.728 & 0.26 \\
\hline & 4.242 & 0.893 & 0.523 & 4.263 & 0.775 & 0.414 & & 4.228 & -1.042 & 0.147 & 4.141 & -0.974 & 0.048 \\
\hline \multirow{4}{*}{ blue 56} & 3.791 & 0.933 & 0.277 & 3.776 & 0.835 & 0.127 & & 4.016 & 1.243 & 0.248 & 3.918 & -1.194 & 0.176 \\
\hline & 4.064 & 1.409 & -0.022 & 4.058 & 1.335 & 0.129 & & 3.907 & -1.105 & 0.54 & 3.789 & -1.044 & 0.488 \\
\hline & 4.427 & 1.205 & 0.081 & 4.451 & 1.135 & 0.053 & bluc 68 & 4.475 & -0.904 & 0.43 & 4.424 & 0.828 & 0.358 \\
\hline & 4.181 & 0.760 & 0.360 & 4.190 & 0.603 & 0.197 & & 4.446 & -1.143 & 0.253 & 4.389 & -1.081 & 0.182 \\
\hline olue 57 & 4.646 & 0.237 & 0.440 & 4.704 & 0.377 & 0.381 & & 3.777 & -1.744 & 0.31 & 3.711 & -1.68 & 0.233 \\
\hline & 4.345 & 0.163 & 0.139 & 4.368 & 0.284 & 0.047 & blue 69 & 4.011 & -1.707 & 0.654 & 4.084 & -1.869 & 0.7 \\
\hline & 4.234 & 0.364 & 0.505 & 4.237 & 0.543 & 0.457 & & 3.911 & -1.858 & 0.161 & 4.03 & -1.965 & 0.161 \\
\hline lue 58 & 4.000 & 0.513 & 0.254 & 3.990 & 0.609 & 0.077 & & 4.368 & -1.29 & 0.237 & 4.474 & -1.411 & 0.272 \\
\hline & 4.122 & 0.389 & 0.200 & 4.121 & 0.451 & 0.041 & & 4.535 & -1.065 & 0.573 & 4.686 & -1.131 & 0.58 .5 \\
\hline & 4.008 & 0.262 & 0.158 & 4.000 & 0.316 & 0.029 & & 4.519 & -1.07 & 0.832 & 4.75 & 1.204 & 0.867 \\
\hline & 3.750 & 0.314 & 0.194 & 3.759 & 0.357 & 0.091 & & 4.28 & -1.357 & 0.98 & 4.448 & -1.481 & 1.019 \\
\hline & 3.739 & 0.619 & 0.310 & 3.727 & 0.658 & 0.229 & blue 70 & 4.951 & 0.828 & 0.91 & 4.99 & -0.565 & 0.857 \\
\hline lue 59 & 4.196 & 0.377 & 0.421 & 4.063 & 0.305 & 0.308 & & 5.128 & 0.896 & 0.886 & 5.163 & -0.799 & 0.756 \\
\hline & 4.623 & 0.153 & 0.200 & 4.535 & 0.051 & 0.100 & & 5.182 & -1.386 & 0.66 & 5.197 & -1.323 & 0.502 \\
\hline & 4.527 & -0.134 & 0.617 & 4.432 & -0.213 & 0.532 & & 4.516 & -1.163 & 0.737 & 4.433 & -1.101 & 0.575 \\
\hline & 4.149 & 0.095 & 0.780 & 4.015 & -0.040 & 0.705 & & 4.587 & -0.981 & 0.824 & 4.529 & -0.885 & 0.69 \\
\hline lue 60 & 3.964 & 0.215 & 0.29 & 4.035 & 0.313 & 0.213 & red 50 & 5.115 & 2.418 & 0.191 & 5.044 & 2.429 & 0.065 \\
\hline & 3.958 & 0.1 & 0.213 & 4.016 & 0.164 & 0.107 & & 5.108 & 2.655 & 0.194 & 5.047 & 2.709 & 0.056 \\
\hline & 3.74 & 0.066 & 0.136 & 3.732 & 0.114 & 0.001 & & 5.529 & 2.59 & 0.081 & 5.503 & 2.599 & 0.067 \\
\hline & 3.71 & 0.275 & 0.266 & 3.717 & 0.377 & 0.163 & & 5.197 & 1.989 & 0.167 & 5.153 & 1.942 & 0.013 \\
\hline lue 61 & 3.45 & 0.276 & 0.606 & 3.319 & 0.301 & 0.497 & & 4.965 & 2.098 & 0.23 & 4.919 & 2.086 & 0.102 \\
\hline & 3.66 & 0.575 & 0.389 & 3.499 & 0.611 & 0.295 & red 51 & 4.955 & 1.824 & 0.555 & 5.077 & 1.753 & 0.495 \\
\hline & 3.585 & 0.195 & 0.345 & 3.404 & 0.24 & 0.248 & & 4.672 & 1.772 & 0.277 & 4.751 & 1.718 & 0.168 \\
\hline & & & & & & & & 4.767 & 2.352 & 0.214 & 4.864 & 2.332 & 0.114 \\
\hline
\end{tabular}




\begin{tabular}{|c|c|c|c|c|c|c|c|c|c|c|c|c|c|}
\hline \multirow[t]{4}{*}{ red 52} & 6.126 & 2.093 & 0.512 & 6.107 & 2.221 & 0.465 & \multirow[t]{5}{*}{ red 63} & 5.088 & -0.124 & 1.105 & 4.992 & -0.089 & 1.046 \\
\hline & 5.997 & 1.818 & 0.053 & 5.968 & 1.905 & -0.011 & & 5.286 & 0.229 & 1.041 & 5.197 & 0.275 & 0.954 \\
\hline & 5.577 & 1.872 & 0.471 & 5.464 & 1.964 & 0.43 & & 5.483 & 0.288 & 0.904 & 5.404 & 0.359 & 0.828 \\
\hline & 5.587 & 1.957 & 0.635 & 5.523 & 2.094 & 0.579 & & 6.173 & -0.305 & 0.225 & 6.139 & -0.279 & 0.097 \\
\hline \multirow[t]{5}{*}{ red 53} & 5.655 & 1.784 & 0.405 & 5.756 & 1.801 & 0.411 & & 5.544 & -1.322 & 0.454 & 5.466 & -1.315 & 0.349 \\
\hline & 5.675 & 1.687 & 0.159 & 5.78 & 1.72 & 0.153 & \multirow[t]{3}{*}{ red 64} & 5.257 & -0.879 & 0.685 & 5.125 & -0.839 & 0.66 \\
\hline & 5.519 & 2.094 & 0.126 & 5.633 & 2.133 & -0.127 & & 5.272 & -1.097 & 0.351 & 5.103 & -1.054 & 0.307 \\
\hline & 5.489 & 2.225 & 0.146 & 5.592 & 2.325 & 0.133 & & 5.185 & -1.194 & 0.63 & 5.029 & -1.139 & 0.586 \\
\hline & 5.506 & 2.187 & 0.222 & 5.634 & 2.248 & 0.227 & \multirow{3}{*}{ red 65} & 5.492 & -1.369 & 0.725 & 5.529 & -1.423 & 0.577 \\
\hline \multirow[t]{3}{*}{ red 54} & 5.558 & 1.929 & 0.158 & 5.557 & 1.883 & 0.022 & & 5.538 & -1.01 & $\begin{array}{l}0.667 \\
0.772\end{array}$ & $\begin{array}{l}5.559 \\
-5003\end{array}$ & -0.951 & $\begin{array}{l}0.469 \\
0.655\end{array}$ \\
\hline & $\begin{array}{l}5.398 \\
5.814\end{array}$ & $\begin{array}{l}2.305 \\
2037\end{array}$ & 0.109 & 5.399 & $\begin{array}{l}2.292 \\
07\end{array}$ & -0.001 & & 5.792 & -1.121 & 0.772 & 5.883 & -1.131 & 0.655 \\
\hline & & & 0.1. & 0.913 & 1.91 & 0.011 & \multirow[t]{3}{*}{ red 66} & 5.938 & -0.986 & 0.658 & $\begin{array}{l}5.827 \\
6.061\end{array}$ & $\begin{array}{r}-0.995 \\
-1018\end{array}$ & \\
\hline \multirow{2}{*}{ red 55} & $\begin{array}{l}5.747 \\
5.704\end{array}$ & $\begin{array}{l}2.091 \\
162\end{array}$ & 0.581 & $\begin{array}{l}5.668 \\
5.508\end{array}$ & & & & $\begin{array}{l}6.129 \\
6.175\end{array}$ & $\begin{array}{r}-1.05 / \\
-1.708\end{array}$ & $\begin{array}{l}0.46 \\
0.412\end{array}$ & $\begin{array}{l}0.001 \\
6.08\end{array}$ & $\begin{array}{r}1.010 \\
-1.726\end{array}$ & $\begin{array}{l}0.3 .38 \\
0.31\end{array}$ \\
\hline & 5.51 & $\begin{array}{l}1.02 \\
1.643\end{array}$ & 0.805 & $\begin{array}{l}5.590 \\
5.238\end{array}$ & 1.695 & 0.711 & & 5.854 & -1.361 & 0.745 & 5.657 & -1.402 & 0.689 \\
\hline \multirow{3}{*}{ red 57} & 5.587 & 1.666 & 0.42 & 5.502 & 1.577 & 0.418 & \multirow[t]{4}{*}{ red 67} & 5.183 & -2.199 & 0.965 & 5.229 & -2.292 & 0.886 \\
\hline & 5.768 & 1.664 & 0.143 & 5.694 & 1.576 & -0.187 & & 4.735 & -2.125 & 0.666 & 4.737 & -2.209 & 0.571 \\
\hline & 6.06 & 1.419 & 0.083 & 6.008 & 1.312 & 0.058 & & 4.985 & -1.859 & 0.529 & 5.01 & -1.918 & 0.421 \\
\hline \multirow[t]{5}{*}{ red 58} & 6.047 & 1.419 & 0.479 & 5.91 & 1.408 & 0.37 & & 5.388 & -2.013 & 0.884 & 6 & & 0.808 \\
\hline & 6.16 & 1.648 & 0.38 & 6.025 & 1.684 & 0.316 & \multirow[t]{5}{*}{ red 68} & 5.615 & -1.78 & 0.615 & 5.569 & -1.745 & 0.509 \\
\hline & 6.471 & 1.7 & 0.143 & 6.393 & 1.712 & 0.032 & & 5.752 & -1.777 & 0.554 & 5.72 & -1.699 & 0.451 \\
\hline & 6.508 & 1.22 & 0.147 & 6.435 & 1.18 & 0.029 & & 5.933 & -1.962 & 0.399 & 5.916 & -1.916 & 0.269 \\
\hline & 6.033 & 1.195 & 0.505 & 5.946 & 1.183 & 0.408 & & 5.264 & -2.608 & 0.448 & 5.187 & -2.598 & 0.323 \\
\hline \multirow[t]{5}{*}{ red 59} & 5.466 & 1.172 & 0.745 & 5.368 & 1.164 & 0.631 & & & & 696 & 098 & -2.076 & 0.604 \\
\hline & 5.788 & 1.323 & 0.461 & 5.693 & 1.335 & 0.347 & \multirow[t]{3}{*}{ red 69} & 4.814 & 2.178 & 0.638 & 4.74 & -2.272 & 0.602 \\
\hline & 6.159 & 0.887 & 0.197 & 6.101 & 0.902 & 0.057 & & 5.126 & -2.218 & 0.374 & 5.077 & 2.328 & 0.326 \\
\hline & $\begin{array}{l}6.162 \\
5.906\end{array}$ & 0.064 & 0.278 & 6.169 & 0.107 & 0.107 & & 5.229 & -2.415 & 0.81 & 5.192 & -2.554 & 0.796 \\
\hline & $\begin{array}{l}5.900 \\
5.574\end{array}$ & $\begin{array}{l}0.02 \\
0.16\end{array}$ & $\begin{array}{l}0.5 \\
0.759\end{array}$ & & & & red 70 & 5.272 & -2.232 & 0.373 & 5.133 & -2.154 & 0.338 \\
\hline \multirow[t]{3}{*}{ red 60} & & & & & & & & $\begin{array}{l}5.063 \\
5.041\end{array}$ & $\begin{array}{l}-2.807 \\
-2.725\end{array}$ & $\begin{array}{l}0.365 \\
0.835\end{array}$ & & $\begin{array}{r}2.768 \\
-2.682\end{array}$ & $\begin{array}{l}0.322 \\
0.826\end{array}$ \\
\hline & 5.115 & $\begin{array}{l}0.863 \\
1.174\end{array}$ & $\begin{array}{l}0.81 / \\
0.643\end{array}$ & $\begin{array}{l}7.0+0 \\
5.209\end{array}$ & 1.123 & 0.457 & \multirow{2}{*}{ red 71} & & & & & & \\
\hline & 5.182 & 1.112 & 0.73 & 5.234 & 0.993 & 0.605 & & 5.44 & $\begin{array}{r}2.558 \\
-2586\end{array}$ & $\begin{array}{l}0.807 \\
0.764\end{array}$ & $\begin{array}{l}5.384 \\
5694\end{array}$ & $\begin{array}{r}-2.408 \\
-2381\end{array}$ & \\
\hline \multirow[t]{5}{*}{ red 61} & 4.958 & -0.06 & 0.846 & 4.949 & -0.076 & 0.726 & \multirow{9}{*}{ red 72} & $\begin{array}{l}5.003 \\
5.848\end{array}$ & 2.815 & 0.68 & 5.863 & -2.761 & 0.482 \\
\hline & 4.61 & 0.033 & 0.84 & 4.581 & 0.015 & 0.74 & & 5.531 & -3.132 & 0.658 & 5.518 & -3.143 & 0.522 \\
\hline & 4.909 & 0.446 & 0.842 & 4.861 & 0.453 & 0.711 & & 5.161 & -2.976 & 0.755 & 5.106 & -2.964 & 0.663 \\
\hline & 5.174 & 0.918 & 0.843 & 5.165 & 0.994 & 0.522 & & 5.225 & 2.719 & 0.805 & 5.124 & -2.623 & 0.574 \\
\hline & 5.776 & 0.19 & 0.858 & 5.805 & 0.179 & 0.728 & & 5.696 & -2.523 & 0.566 & 5.594 & -2.617 & 0.542 \\
\hline \multirow[t]{4}{*}{ red 62} & 5.719 & 0.13 & 0.585 & 5.597 & 0.163 & 0.498 & & 5.744 & -2.512 & 0.4 & 5.648 & -2.581 & 0.329 \\
\hline & 6.118 & 0.185 & 0.211 & 6.089 & 0.25 & 0.085 & & 5.877 & -2.629 & 0.381 & 5.839 & -2.739 & 0.309 \\
\hline & 6.149 & 0.023 & 0.141 & 6.1 & 0.042 & -0.018 & & 5.87 & -2.683 & 0.56 & 5.821 & -2.804 & 0.551 \\
\hline & 6.036 & -0.204 & 0.196 & 5.921 & -0.198 & 0.055 & & & & & & & \\
\hline
\end{tabular}

